2006s-16

\title{
Actions and Beliefs: Estimating Distribution-Based Preferences Using \\ a Large Scale Experiment with \\ Probability Questions on Expectations
}

\author{
Charles Bellemare, Sabine Kröger, \\ Arthur van Soest
}

Série Scientifique
Scientific Series

Montréal

Septembre 2006

(C) 2006 Charles Bellemare, Sabine Kröger, Arthur van Soest. Tous droits réservés. All rights reserved.

Reproduction partielle permise avec citation du document source, incluant la notice (C).

Short sections may be quoted without explicit permission, if full credit, including (C) notice, is given to the source.
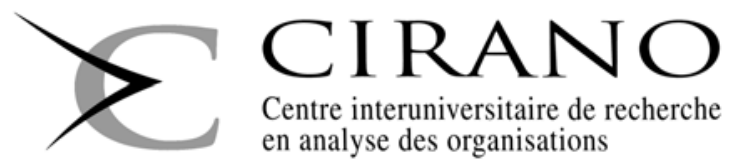

Centre interuniversitaire de recherche en analyse des organisations 


\section{CIRANO}

Le CIRANO est un organisme sans but lucratif constitué en vertu de la Loi des compagnies du Québec. Le financement de son infrastructure et de ses activités de recherche provient des cotisations de ses organisations-membres, d'une subvention d’infrastructure du Ministère du Développement économique et régional et de la Recherche, de même que des subventions et mandats obtenus par ses équipes de recherche.

CIRANO is a private non-profit organization incorporated under the Québec Companies Act. Its infrastructure and research activities are funded through fees paid by member organizations, an infrastructure grant from the Ministère du Développement économique et régional et de la Recherche, and grants and research mandates obtained by its research teams.

\section{Les partenaires / The Partners}

\section{Partenaire majeur}

Ministère du Développement économique, de l'Innovation et de l'Exportation

\section{Entreprises partenaires}

Alcan inc.

Banque du Canada

Banque Laurentienne du Canada

Banque Nationale du Canada

Banque Royale du Canada

Bell Canada

BMO Groupe financier

Bombardier

Bourse de Montréal

Caisse de dépôt et placement du Québec

Fédération des caisses Desjardins du Québec

Gaz Métro

Hydro-Québec

Pratt \& Whitney Canada

Raymond Chabot Grant Thornton

Autres partenaires gouvernementaux

Industrie Canada

Ministère des Finances du Québec

Ville de Montréal

\section{Partenaires universitaires}

École Polytechnique de Montréal

HEC Montréal

McGill University

Université Concordia

Université de Montréal

Université de Sherbrooke

Université du Québec

Université du Québec à Montréal

Université Laval

Le CIRANO collabore avec de nombreux centres et chaires de recherche universitaires dont on peut consulter la liste sur son site web.

Les cahiers de la série scientifique (CS) visent à rendre accessibles des résultats de recherche effectuée au CIRANO afin de susciter échanges et commentaires. Ces cahiers sont écrits dans le style des publications scientifiques. Les idées et les opinions émises sont sous l'unique responsabilité des auteurs et ne représentent pas nécessairement les positions du CIRANO ou de ses partenaires.

This paper presents research carried out at CIRANO and aims at encouraging discussion and comment. The observations and viewpoints expressed are the sole responsibility of the authors. They do not necessarily represent positions of CIRANO or its partners. 


\title{
Actions and Beliefs: Estimating Distribution-Based Preferences Using a Large Scale Experiment with Probability Questions on Expectations*
}

\author{
Charles Bellemare ${ }^{\dagger}$, Sabine Kröger ${ }^{\ddagger}$, Arthur van Soest ${ }^{\S}$
}

\begin{abstract}
Résumé / Abstract
Afin de déceler un modèle structurel de prise de décision dans l'incertitude, nous combinons les données recueillies par i) les choix des deux types de joueurs dans le jeu de l'ultimatum (ceux qui proposent et ceux qui répondent), ii) leurs attentes obtenues sous la forme de questions à probabilité subjective, et iii) les choix des dictateurs (premiers joueurs) dans le jeu du dictateur. Nous utilisons un large échantillon représentatif des sujets dans la population néerlandaise. Nos résultats indiquent une hétérogénéité considérable dans la population sur les préférences en matière d'équité. La diversité de ces préférences a un impact important sur les décisions des dictateurs dans le jeu du dictateur, et sur les répondeurs dans le jeu de l'ultimatum, mais un impact plutôt moindre sur les décisions des joueurs qui proposent dans le jeu de l'ultimatum. Cette dernière observation est due aux attentes subjectives de ces joueurs face aux décisions des répondeurs. Le modèle qui utilise des données subjectives sur les attentes des joueurs prévoit mieux les choix des sujets et réduit plus le bruit qu'un modèle qui suppose que les joueurs ont des attentes rationnelles.
\end{abstract}

Mots clés : attentes subjectives, aversion à l'injustice, jeu de l'ultimatum

We combine the choice data of proposers and responders in the ultimatum game, their expectations elicited in the form of subjective probability questions, and the choice data of proposers ("dictators") in a dictator game to estimate a structural model of decision making under uncertainty. We use a large and representative sample of subjects drawn from the Dutch population. Our results indicate that there is considerable heterogeneity in preferences for equity in the population. Changes in preferences have an important impact on decisions of dictators in the dictator game and responders in the ultimatum game, but a smaller impact on decisions of proposers in the ultimatum game, a result due to proposer's subjective expectations about responders' decisions. The model which uses subjective data on expectations has better predictive power and lower noise level than a model which assumes that players have rational expectations.

Keywords: inequity aversion, subjective expectations, ultimatum game

Codes JEL : C93, D63, D84

\footnotetext{
* We thank Vera Toepoel, Marcel Das and his team at CentERdata for support throughout the experiment. The first author thanks the Canada Chair of Research in the Economics of Social Policies and Human Resources for support.

† Département d’économique, Université Laval, CIRPÉE, IZA, email: cbellemare@ecn.ulaval.ca

‡ Economic Science Laboratory, University of Arizona, email: s.kroger@econlab.arizona.edu

§ RAND and Tilburg University, email: avas@uvt.nl
} 


\section{Introduction}

Individual decision making under uncertainty plays an important role in economic theory and practice. Economic models of choice under uncertainty typically assume that agents have a probability distribution over the uncertain outcomes and combine this with their preferences in order to choose the optimal alternative. Experiments of proposal and response such as the ultimatum game have been used to understand the preference structures of the decision making agents. In such games, the proposers' payoffs not only depend on their own actions, but also on the uncertain reactions of responders to the proposers' choices, so that the proposers' decisions will in general depend on their expectations about the behavior of responders.

This paper shows, with the specific example of the ultimatum game, how the empirical content of experiments of proposal and response can be improved in several ways. First, as shown by Manski (2002), many experimental studies have to rely on assumptions on agents' expectations about other players' actions or other uncertainty (such as rational expectations) in order to identify preferences, since observed choice data is generally not rich enough to uncover both expectations ('beliefs') and preferences. An exception is Nyarko and Schotter (2002), who collect data on actions and beliefs in a laboratory setting for repeated two player games with simultaneous decision making. They find that players are more likely to best-respond to their stated beliefs than to beliefs inferred by the analyst from past decisions. Following Nyarko and Schotter (2002) and Manski (2004), we address the identification problem in Manski (2002) by collecting data on the proposers' subjective probability distributions over the actions taken by responders, in addition to the usual experimental data. Thus we ask the proposers direct questions on what they think are the probabilities that their responder will make certain decisions.

Second, following the recent trend set by, for instance, Harrisson, Lau and Williams (2002) ${ }^{1}$ we use a large representative sample of the Dutch population rather than a

\footnotetext{
${ }^{1}$ Other studies using representative samples are Bellemare and Kröger (2004), and Fehr, Fischbacher,
} 
convenience sample of, for example, students, as used in much of the experimental literature. The individuals in the sample were randomly assigned to a specific role, and are thus all drawn from the same population distribution of preferences and beliefs. This makes the analysis useful for making inference on a broad population.

Our non-homogeneous sample raises the issue of heterogeneity in preferences and beliefs. A third important feature of our work is that we develop a rich econometric model incorporating ("observed") heterogeneity explained by background characteristics such as age and education level as well as ("unobserved") heterogeneity that cannot be captured by such characteristics.

A fourth distinctive feature of the model is that it is structural in the sense that it explicitly disentangles preferences and beliefs about the reactions of responders. Unlike other investigations which have incorporated subjective expectations data in an empirical choice model, our model also allows for correlation between preferences and beliefs of proposers. Thus, for example, we allow for the possibility that proposers with optimistic beliefs about the actions of responders also have systematically different preferences, leading to a spurious correlation between beliefs and actions and inducing an endogeneity bias in the estimates of the preference parameters. We avoid this bias and are able to make causal inferences on the effect of beliefs on choices of proposers in the game.

Our application concerns preferences and beliefs for inequity aversion, an issue that has received a lot of attention in the recent experimental literature. We use the model for linear asymmetric inequity aversion introduced by Fehr and Schmidt (1999), distinguishing inequity aversion resulting from having a higher from that of having a lower payoff than the other player. This model can explain the common finding in ultimatum game experiments that many proposers make equitable offers, in contrast with the traditional sub game equilibrium prediction that offers should not exceed the smallest positive amount that can be offered. The latter "traditional" prediction rests on the two assumptions that proposers maximize their own expected monetary Von Rosenbladt, Schupp, and Wagner (2002). 
payoffs and expect responders not to reject any positive offer (for example, because proposers think responders also maximize their own monetary payoffs). Thus both preferences leading to deviations from expected pay-off maximization, and the belief that not everyone accepts any positive offer could explain why experimental results are out of line with the traditional prediction. Our framework and the data on beliefs are particularly suited to disentangle these two explanations.

Our sample is randomly split up in four groups: proposers and responders in the ultimatum game, and proposers ("dictators") and passive responders (receivers) in the dictator game. The proposers in the ultimatum game are not only asked how much they want to offer to the other player, but are also asked about their subjective probabilities that responders will accept or reject any possible offer. Actions of responders in the ultimatum game are elicited using the strategy method, requiring responders to indicate their intended action for all possible offers that can be made to them. Our model is estimated combining all this information.

Our results can be summarized as follows. First, we find substantial deviations between the average subjective acceptance probabilities reported by the proposers and the actual acceptance rates in the responder data.

Second, we find that the model which incorporates proposers' subjective probability distributions over all possible actions of responders provides a better fit to the observed choice distribution than a model which assumes that proposers have rational expectations. This mirrors Nyarko and Shotter (2002) finding that choice models using subjective probability distributions provide a better fit to the actions in two by two normal form games.

Third, we find substantial unobserved heterogeneity in the subjective probabilities as well as in preferences for inequity aversion, with a strong positive correlation between optimism and inequity aversion.

Fourth, we find that aversion for inequity to own and other's disadvantage declines as subject's level of education increases, and aversion for inequity towards other's disadvantage increases with age. Combining these effects, we find that of all the sub- 
groups of the population our model can distinguish on the basis of observable characteristics, subjects with high levels of education, below 30 years of age, and not participating in the labor market, have the most egoistic preferences in the sense that their predicted behavior in the experiment comes the closest to what is predicted by the traditional paradigm of maximizing own pay-off. This suggests that inequity aversion is much larger in the Dutch population as a whole than extrapolations based on student samples would suggest.

The rest of this paper is organized as follows. Section 2 presents our experimental design. Section 3 presents our approach to identify the economic parameters of interest. Section 4 presents some descriptive statistics of our sample, and summary statistics of the choice decisions in the experiment. Section 5 discusses the estimation results of the structural model, and presents simulations to assess the fit and the implications of the model for observed behavior. Section 6 concludes.

\section{Experiment}

Our subjects were recruited by CentERdata, the survey research institute affiliated to Tilburg University in the Netherlands. The main activity of CentERdata is to manage and carry out panel surveys through an Internet panel: the CentERpanel (hereafter $\mathrm{CP})$, consisting of approximately 2000 Dutch households. Every Friday, CP's household members receive a questionnaire which they are asked to fill in at any time between that Friday and the Tuesday of the following week. This is done at home, either on their computer or using a television set connected to a set-up box linking the household to the CentERdata server. In order to keep the sample representative of the Dutch population, households without a computer or a television set are given the necessary equipment. $^{2}$

\footnotetext{
${ }^{2}$ For a description of the recruitment, sampling methods, and past usages of the CentERpanel see: www.centerdata.nl. Children below 16 years of age as well as immigrants are excluded from the panel, the latter group for the reason that low language proficiency in Dutch makes it difficult to answer the
} 
There are many reasons why the $\mathrm{CP}$ is an attractive medium to conduct experiments. First, it gives access to a representative sample of a population, which is one of the key features of our study. Second, because participants answer questions on a computer, we are able to replicate the environment of a laboratory experiment, which simplifies comparisons of our results with those of the existing literature. Third, the experiment is double blind as participants were told that they will be anonymously matched and that their identities are not revealed to the experimenters. Finally, as CentERdata reimburses the weekly telephone costs for answering the questionnaire by crediting CentERpoints (100 CentERpoint $=1$ Euro) to the respondents' bank accounts four times a year, our participants are already familiar with payment in fictitious currency. This allows us to use CentERpoints as the experimental currency unit and reimburse our participants in a convenient way.

We randomly assigned the participants of the CentERpanel to the "ultimatum game" or the "dictator game." In both games, two persons, a proposer and a responder, ${ }^{3}$ can share an amount of 1000 CentERpoints (10 Euros). ${ }^{4}$ In the ultimatum game the proposer suggests an allocation to the responder. We discretized the choice set of the proposer to eight possible allocations: $A \in\{(1000,0),(850,150),(700,300),(550,450)$, $(450,550), \ldots,(0,1000)\}$ where the first and second amount denote the payoffs for the proposer and the responder, respectively. Responders made their choices using the strategy method, asking them for each of the eight allocations that could be offered whether they would accept or reject. The response which corresponded to the actual decision of the proposer matched to this responder determined the payoff of both parquestions on a weekly basis.

${ }^{3}$ For ease of reading we keep the terms "proposer" and "responder" for the different roles. In the experiment we avoided suggestive labels and referred to the persons themselves and the "matched panel member." Computer screens of the original experiment (in Dutch) and a translated version are available upon request.

${ }^{4}$ Carpenter, Burks, and Verhoogen (2005) find that in laboratory ultimatum and dictator games, there are no significant differences in the actions of the players when the stakes are raised from 10 U.S. dollars (approximately 8.5 Euros) to 100 U.S. dollars. 
ticipants.

After all participants had made their decisions, proposers and responders were randomly matched and payoffs were computed based on the decisions of the pair. The final payoffs were computed as follows: if the proposer had offered the allocation $(X, Y)$ and the responder had stated he or she would accept this allocation, responder and proposer received the amount according to this allocation, i.e., the responder received $X$ and the proposer received $Y$ CentERpoints. If the offer was rejected, the proposer and the responder both received nothing.

In the dictator game the responder had no active role. Both players received the payoffs determined by the proposer (which is why this game is referred to as "dictator game").

The strategy method was chosen to overcome the difficulty of having CP members interact in real time. This method has the additional advantage of providing more information, as the responses to all eight possible allocations are elicited, including allocations that are never or hardly ever chosen by the actual proposers. ${ }^{5}$

The beliefs of proposers in the ultimatum game were elicited with a series of subjective probability questions. Eliciting subjective probabilities is cognitively demanding. To simplify the respondents' task, probabilities were obtained by asking subjects how many out of 100 persons would accept/reject each offer, or how many out of 100 persons would offer a given allocation. ${ }^{6}$ In order to be able to account for framing effects resulting from the phrasing of the question, approximately half of the participants were asked to state their subjective acceptance probabilities for each possible offer, while the other half were asked to state their rejection probabilities. Also, in order to circumvent the possibility that belief elicitation influences behavior, these questions were asked after players had made their decisions. Subjects were not rewarded based on the accu-

\footnotetext{
${ }^{5}$ McLeish and Oxoby (2004) find that decisions in the ultimatum game collected with the strategy method are not statistically different from decisions collected in a hot environment.

${ }^{6}$ This follows Hoffrage, Lindsey, Hertwig, and Gigerenzer (2000) who find that people are better at working with natural frequencies than with percent probabilities.
} 
racy of their expectations. ${ }^{7}$ This concluded the experimental part of the session.

The experiment was conducted in March 2004. Individuals contacted had to read an opening screen informing them that they were selected to participate in an experiment conducted by a team of university researchers. A detailed description of the game and an explanation of the payoff structure followed. Each person was informed that conditional on their participation, they would be randomly assigned to one of the roles and would be randomly matched to another panel member playing the opposite role. The role was revealed once a panel member had agreed to participate. We contacted 1410 panel members of whom 130 declined to participate and 17 did not react. Of the 1263 panel members who completed the experiment, 389 (268) were proposers and 355 (251) were responders in the ultimatum (dictator) game. ${ }^{8}$ As announced before the experiment, each participant received information on the outcome of the game and their final payoff two weeks after the experiment, and this amount was later credited to their CentER bank account.

\section{An Empirical Model of Preferences and Beliefs}

In this section we will introduce an econometric model to explain the behavior of proposers and responders in the ultimatum game and proposers in the dictator game, as well as the acceptance or rejection probabilities reported by the proposers in the ul-

\footnotetext{
${ }^{7}$ There are theoretical grounds suggesting that beliefs elicited by paying subjects for the accuracy of their beliefs using the quadratic scoring rule (Selten, 1967) should be lead to more precise disclosure of individual expectations than not paying or paying a flat fee, but the empirical evidence seems not to support this. Ortmann, Fitzgerald, and Boeing (2000) find that unpaid participants in their experiment had surprisingly accurate estimates of the average actions; both Friedman and Massaro (1998) and Sonnemans and Offerman (2001) find insignificant differences between using the quadratic scoring rule or paying subjects a flat fee.

${ }^{8}$ Note that the number of responders exceeds the number of proposers. In order to balance the unequal numbers of players in both roles, 8 proposers were randomly assigned twice to a responder. As all other participants, those 8 proposers received payments resulting from only one (the first) matching.
} 
timatum game. The model is structural in the sense that preferences and beliefs are explicitly separated. We allow for heterogeneity of both preferences and beliefs across the population. Preferences and beliefs can vary with observed characteristics such as age, education level, labor force status, and gender (a vector $x_{i}$ of observed individual characteristics) and with unobserved characteristics.

\section{Preferences with Inequity Aversion}

We incorporate inequity aversion in preferences following Fehr and Schmidt (1999), allowing for different disutilities of having more and having less than the opponent. In the case of no uncertainty, the utility to player $i$ from pay-offs $y_{\text {self }}$ to him- or herself and $y_{\text {other }}$ to the other player is given by:

$$
u_{i}\left(y_{\text {self }}, y_{\text {other }}\right)=y_{\text {self }}-\alpha_{i} \max \left\{y_{\text {other }}-y_{\text {self }}, 0\right\}-\beta_{i} \max \left\{y_{\text {self }}-y_{\text {other }}, 0\right\}
$$

For respondents who only care about their own pay-off, $\alpha_{i}$ and $\beta_{i}$ would be equal to 0 . If respondents are inequity averse, $\alpha_{i}$ and $\beta_{i}$ will be positive. If $\beta_{i}$ is smaller than $\alpha_{i}$, then, keeping the own pay-off constant, the per ("CentER") point disutility of having less than the other player is larger than the per point disutility of having more than the other player.

To allow for heterogeneous preferences across the population, we will allow the parameters $\alpha_{i}$ and $\beta_{i}$ to vary across respondents $i$, using the following specification:

$$
\alpha_{i}=e^{x_{i}^{\prime} \alpha+u_{i}^{\alpha}} ; \beta_{i}=e^{x_{i}^{\prime} \beta+u_{i}^{\beta}}
$$

Here $u_{i}^{\alpha}$ and $u_{i}^{\beta}$ reflect unobserved heterogeneity. We will assume that $\left(u_{i}^{\alpha}, u_{i}^{\beta}\right)$ is independent of error terms and background variables $x_{i}$ and follows a bivariate normal distribution with mean zero and arbitrary covariance matrix. We expect a positive correlation between $u_{i}^{\alpha}$ and $u_{i}^{\beta}$ since people with a general aversion to inequity will have large values for both.

For proposers in the dictator game, equations (1) and (2) are sufficient to describe their optimal choice, since they face no uncertainty. Moreover, in the dictator game 
the sum of the two pay-offs is given and is always the same, and it can be normalized to 1 (1,000 CentER points or 10 Euro, in our experiment), implying that $y_{\text {other }}$ equals $1-y_{\text {self }}$. As discussed in the previous section, each proposer was asked to choose from a set of eight amounts $(j=1, \ldots, 8)$, involving pay-offs $y_{\text {prop }}(1), \ldots, y_{\text {prop }}(8)$. Perfectly optimizing behavior in the dictator game would therefore imply that proposer $i$ chooses the option $j$ that maximizes

$$
v_{i j}^{D}=y_{\text {prop }}(j)-\alpha_{i} \max \left\{1-2 y_{\text {prop }}(j), 0\right\}-\beta_{i} \max \left\{2 y_{\text {prop }}(j)-1,0\right\}
$$

To allow for the fact that some proposers in the dictator game will make suboptimal choices, we add idiosyncratic error terms $\lambda^{D} \epsilon_{i j}$ to the true utilities $v_{i j}^{D}$, and assume that respondent $i$ chooses the option $j$ that maximizes $v_{i j}^{D}+\lambda^{D} \epsilon_{i j}$ rather than $v_{i j}^{D}$. We assume that the errors $\epsilon_{i j}$ are independent of each other and of other variables in the model (such as the unobserved heterogeneity terms and the observed characteristics $\left.x_{i}\right)$, and follow a Generalized Extreme Value type I (GEV(I)) distribution. This gives rise to the familiar multinomial logit probabilities:

$$
P\left(\text { Proposer } i \text { chooses } j \mid v_{i 1}^{D}, \ldots, v_{i 8}^{D}\right)=\frac{e^{v_{i j}^{D} / \lambda^{D}}}{\sum_{k=1}^{8} e^{v_{i k}^{D} / \lambda^{D}}}
$$

The parameter $\lambda^{D}$ indicates the importance of sub-optimal behavior of the proposers in the dictator game. If they behave optimally, $\lambda^{D}$ is zero. If their behavior were equivalent to random choice, with no role for the utility values, then $\lambda^{D}$ would be infinitely large.

Proposers in the ultimatum game are faced with uncertainty, since they do not know whether their offer will be accepted or rejected. We will assume expected utility maximization, based upon proposer $i$ 's specific subjective probability $Q_{i}(j)$ that offer $j$ will be accepted. Since the utility is zero if the offer is rejected, the expected utility of offer $j$ is given by $v_{i j}^{U}=Q_{i}(j) v_{i j}^{D}$. Allowing for sub-optimal behavior in the same way as before, with noise-to-signal ratio parameter $\lambda^{U}$, this gives the following choice probabilities for proposers in the ultimatum game: 


$$
P\left(\text { Proposer } i \text { chooses } j \mid v_{i 1}^{U}, \ldots, v_{i 8}^{U}\right)=\frac{e^{v_{i j}^{U} / \lambda^{U}}}{\sum_{k=1}^{8} e^{v_{i k}^{U} / \lambda^{U}}}
$$

For responders in the ultimatum game, the uncertainty is resolved, making their choice problem deterministic. We will assume that the distribution of preferences among responders is the same as among proposers. This assumption is very plausible, since participants were randomly assigned to the role of proposer or the role of responder. Under these assumptions, responder $i$ who gets an offer $y_{\text {resp }}(j)=1-y_{\text {prop }}(j)$ with $(j=1, \ldots, 8)$ has to trade off the utility of rejecting and the utility of accepting the offer. According to (3), these utility values are $v_{i j}^{R}=0$ and

$$
v_{i j}^{A}=y_{r e s p}(j)-\alpha_{i} \max \left\{1-2 y_{r e s p}(j), 0\right\}-\beta_{i} \max \left\{2 y_{r e s p}(j)-1,0\right\}
$$

A perfect pay-off maximizing responder would thus choose to accept the offer if and only if $v_{i j}^{A}>v_{i j}^{R}(=0)$. To allow for suboptimal behavior, we again add GEV(I) errors that are independent of everything else in the model, multiplied by a noise-to-signal ratio parameter $\lambda^{R}$, and assume the responder maximizes over the contaminated values rather than the exact values, giving the binary logit probability:

$$
P\left(\text { Responder } i \text { accepts offer } j \mid v_{i j}^{A}\right)=\frac{1}{1+e^{-v_{i j}^{A} / \lambda^{R}}}
$$

\section{Beliefs}

In the experiment we ask for each proposer's beliefs, so one approach is to take the reported acceptance or rejection probabilities in the data and plug them into equation (5). Assuming that the reported beliefs are exactly the probabilities that the proposers use in making their decisions and assuming that error terms and unobserved heterogeneity components $\left(u_{i}^{\alpha}, u_{i}^{\beta}\right)$ are independent of these beliefs would then imply that the $Q_{i}(j)$ are observed exogenous variables, and the preference distribution can be estimated without modelling the beliefs. 
There are, however, two reasons why this approach is unlikely to be valid. First, there appears to be a framing effect of asking either rejection or acceptance probabilities: the distribution of the raw data on reported acceptance probabilities differs substantially from the distribution of acceptance probabilities implied by the raw data on reported rejection probabilities (see next section), showing that answers to these questions suffer from framing bias. This framing bias cannot have affected the answers to the choice questions (since the questions on the beliefs that have the "frames" in their wordings come after the questions on the choices), so that the probabilities entering the utility comparison must first be purged of the framing bias in the reported probabilities.

Second, the acceptance probabilities may partly be driven by unobserved heterogeneity that is correlated with the unobserved heterogeneity terms $u_{i}^{\alpha}$ and $u_{i}^{\beta}$ in the preference parameters. The people with high inequity aversion may, for example, tend to be more optimistic and have higher subjective probabilities that their offers will be accepted. Early experiments in cognitive psychology, surveyed in Rapoport and Wallsten (1972), already provided evidence that subjective probabilities are not independent of utilities over outcomes. If this is indeed the case, it leads to correlation between reported acceptance probabilities and the unobserved heterogeneity terms $u_{i}^{\alpha}$ and $u_{i}^{\beta}$ in the choice equations, implying that reported acceptance probabilities are not exogenous in the choice model and that estimates of preferences assuming exogeneity of choice probabilities will be biased.

Both issues can be dealt with by modelling preferences and acceptance and rejection probabilities jointly. We will allow these probabilities to vary with the same individual characteristics $x_{i}$ that relate to preferences. In the raw data, we saw substantial bunching of the reported probabilities at 0 and 1 . We will account for this by modelling censoring at zero and at one, as in a two-limit tobit model. First, we model the true probabilities $Q_{i}(j)$ used in expected utility maximization, not affected by framing or other reporting errors:

The $\gamma$ parameters capture choice specific effects of subjective belief formation. For 


$$
\begin{array}{rlrl}
Q_{i}^{*}(j) & =x_{i}^{\prime} \delta+\gamma_{j}+u_{i}^{P} \\
Q_{i}(j) & =0 & \text { if } & Q_{i}^{*}(j)<0 \\
& =Q_{i}^{*}(j) & \text { if } & 0<Q_{i}^{*}(j)<1 \\
& =1 & \text { if } & Q_{i}^{*}(j)>1
\end{array}
$$

example, we expect them to increase with $j$ as long as amounts remain below the equal split, since proposers will probably realize that acceptance probabilities will rise if the amount offered to the other player increases towards an equal split. Whether $\gamma_{j}$ also increases with $j$ beyond the equal split or not is less clear; here acceptance probabilities (and thus also the beliefs about them) can increase or decrease depending on the extent of inequity aversion. The unobserved heterogeneity term $u_{i}^{P}$ reflects the proposer's optimism or pessimism. We will assume that the three unobserved heterogeneity terms $\left(u_{i}^{\alpha}, u_{i}^{\beta}, u_{i}^{P}\right)$ are jointly normal with mean zero and with arbitrary covariance matrix to be estimated, independent of error terms and of the regressors $x_{i}$.

Reported probabilities $P_{i}(j)$ can deviate from the true probabilities because of framing bias or because of an idiosyncratic reporting error $\epsilon_{i j}^{P}$. The latter is assumed to be i.i.d. normal and independent of everything else. The framing bias at offer $j$ is modelled in a symmetric way, using a parameter $\phi_{j}$. Define a "framing" variable $F_{i}$ which is equal to 1 if the belief questions to proposer $i$ are framed in terms of accepting and equal to -1 if they are framed in terms of rejection. The model for the "reported"9 acceptance probabilities $P_{i}(j)$ is as follows:

$$
\begin{aligned}
P_{i}^{*}(j) & =x_{i}^{\prime} \delta+\gamma_{j}+\phi_{j} F_{i}+u_{i}^{P}+\epsilon_{i j}^{P} \\
P_{i}(j) & =0 \quad \text { if } \quad P_{i}^{*}(j)<0 \\
& =P_{i}^{*}(j) \quad \text { if } \quad 0<P_{i}^{*}(j)<1 \\
& =1 \quad \text { if } \quad P_{i}^{*}(j)>1
\end{aligned}
$$

The raw data (see next section) suggest that the framing parameters $\phi_{j}$ are negative,

\footnotetext{
${ }^{9}$ The reported acceptance probability is defined as one minus the reported rejection probability if the questions are framed in terms of rejection probabilities.
} 
implying that reported acceptance probabilities are too small if the questions ask for probabilities of accepting, and reported probabilities of rejecting are too small if the questions ask for probabilities of rejecting. Imposing symmetry on the framing effects is necessary to identify the framing parameters and the parameters $\gamma_{j}$ in the true probabilities from the reported beliefs alone (i.e., without relying on the data on choices and assumptions on preferences).

\section{Descriptive statistics: sample, choices, and reported be- liefs}

Table 1 gives the description of the explanatory variables we will use in the empirical analysis. The demographic structure of our sample is characterized by a median age of 48. The youngest and oldest participants were 18 and 89 years old. We group our participants in six age categories, each comprising 10 years of age. With the border categories, i.e., participants younger than 25 years ("Age $<25$ ") and more than 64 years of age ("Age $>64$ "), comprising 3\% and 15.5\% of all participants, respectively. Most of our participants are between 35 and 44 years (23\% in "Age 35-44") or between 45 an 54 years (25\% in "Age 45-54") old. Education levels are also arranged in six categories. The variable "Educ1" is a dummy for the lowest level, i.e., primary education (5\% of the sample), and "Educ6" is a dummy for the highest level of education, i.e., university degree (11\% of the sample). For more than half of the participants, the highest degree is from a vocational training school, at a low, intermediate, or high level. $(26 \%, 20 \%$ and $24 \%$, respectively). About $59 \%$ of our subjects are active in the labor force ("Market work"), 12\% are homemakers ("House work"), 16\% are retired and 13\% do not work ("Other"), i.e., are unemployed or students.

Figure 1 presents the choice frequencies of proposers in both the ultimatum game and the dictator game. These distributions exhibit two well-known features (see, e.g., Camerer, 2003): First, proposers send positive amounts, with the mode around the 
equal split, and with very few amounts much above that. Second, the distribution of amounts offered to the other player in the ultimatum game stochastically dominates that in the dictator game.

\section{— Figure 1 about here -}

Table 2 presents the choices of responders in the ultimatum game. Each line of the table presents a choice sequence obtained using the strategy method, and the final column presents the sequence frequencies. Choice sequences are grouped into three categories. The biggest group (53.7\% of all cases) is comprised of threshold players who accept any proposal above a certain amount. Their threshold level is informative of the degree of inequity aversion for cases where they receive less than the other player. The second biggest group (43.3\%) are plateau players, defined as individuals who accept offers in a range which excludes both the minimum and maximum amounts that can be offered. The width of the plateau is informative of the degree of inequity aversion to both own and other's disadvantage (i.e., of $\alpha_{i}$ and $\beta_{i}$ ), as individuals reject offers giving them either extremely advantageous or disadvantageous positions relative to the proposer. Similar levels of plateau behavior in the ultimatum game have been reported in the laboratory (see e.g., Hennig-Schmidt, Li, and Yang, 2004).

\section{— Table 2 about here -}

Finally, the third group plays what we call chain-saw behavior, without any systematic pattern. This group is small (3.0\%) and will be left out of our empirical analysis. ${ }^{10}$

The presence of a sizeable population of plateau types has an immediate consequence for the aggregate acceptance rates, presented at the bottom of Table 2. We find that the acceptance rates increase to above $90 \%$ for proposals around the equal split, before progressively declining to just above $55 \%$ when proposers offer the whole amount to the responder.

\footnotetext{
${ }^{10}$ We also estimated the model including these respondents and found results that were very similar to those we present.
} 
Figure 2 presents the densities of subjective acceptance probabilities of proposers in the ultimatum game for offers of $0 \mathrm{CP}, 450 \mathrm{CP}$, and $1000 \mathrm{CP}$. We see that the mode of the density is concentrated near zero in the case of offers of $0 \mathrm{CP}$, implying that most proposers believe that offers of 0 will not be accepted by the responder. Still, there is also a non-negligible number of proposers expecting that an offer of 0 will certainly be accepted.

\section{— Figure 2 about here -}

The density for offers of $450 \mathrm{CP}$ is quite different - it is centered around $50 \%$. In this case, there is substantial variability in the reported beliefs, with subjective acceptance probabilities varying all over the unit interval.

For offers of $1000 \mathrm{CP}$, we find almost the mirror image of the distribution for offers of $0 \mathrm{CP}$. Almost half of the proposers think an offer of 1,000 CP will certainly be accepted, and about $25 \%$ think the offer will certainly be rejected.

In Figure 2, proposers in the ultimatum game getting the beliefs questions with the accept frame and the reject frame are merged. Figure 3 presents the means of the subjective acceptance probabilities for each amount that could be offered, separately for those who got the accept and the reject frames. There is a significant effect of the question frame, with the accept frame giving lower acceptance probabilities than the reject frame. This effect is smallest for amounts sent of 450 and 550 CentER points. Violation of the additivity axiom of probability, by which the reported likelihood of an event and its complement sum to less than one, seems to be well recognized in the psychology literature on probability judgment; see Lindley, Tversky, and Brown (1979) for a discussion of this phenomenon and related findings.

\section{— Figure 3 about here -}

Interestingly, many proposers in the ultimatum game appear to anticipate the presence of plateau types in the responders population. We see that the acceptance rates expected by proposers level off and even decline with offers in excess of an equal split. 
This result is all the more remarkable since proposers have not had a chance to learn the expected pattern of response, either by having played the game in repetition or by having been responders themselves.

\section{Econometric results}

We estimated the model presented in section 3 by maximum simulated likelihood. Integration over the joint distribution of $\left(u_{i}^{\alpha}, u_{i}^{\beta}, u_{i}^{P}\right)$ was performed by simulation, using 100 draws for each observation based on Halton sequences (see Train, 2003). In order to evaluate the impact of incorporating subjective probability distributions in the model, we estimated a second model assuming that proposers in the ultimatum game had rational expectations about the responders' acceptance rates. In that model, beliefs of all proposers are the same, and set equal to observed aggregate acceptance rates of responders, taken from the bottom row of Table 2. This model is estimated without the equation for beliefs and thus also without correlation between beliefs and unobserved heterogeneity in preferences. ${ }^{11}$ A third model takes the reported "raw" subjective probabilities as exogenous variables reflecting the true probabilities underlying the proposers' decisions.

Table 3 presents the estimated parameters for the first two models, distinguishing the effects of some background characteristics on the inequity aversion parameters $\alpha_{i}$ and $\beta_{i}$, and, in the first model, on the subjective beliefs of proposers in the ultimatum game. Table 4 presents the preference parameters for the third model. Overall, parameter estimates of the inequity aversion equations of the three models are similar. This could be expected since the choice data for senders in the dictator game and responders in the ultimatum game are used in exactly the same way, only the choices of the proposers in the ultimatum game are interpreted differently. Signs in the three models correspond in all but a few cases and so do significance levels. As we will show below,

\footnotetext{
${ }^{11}$ The fact that the acceptance probabilities are estimated was ignored, so that the standard errors in this model are probably slightly underestimated.
} 
the model which uses subjective expectations provides a better fit to the data than the rational expectations model and than the model with reported probabilities taken as exogenous, better reproducing the distribution of choices made by proposers in the ultimatum game.

— Table 3 about here -

— Table 2 about here -

For now, because of the similarity in preference parameters, we will focus our discussion on the determinants of inequity aversion using the model with subjective expectations. A Wald test of the null hypothesis that parameters of the $\alpha$ equation are equal to those of the $\beta$ equation gives a test statistic of $62.21\left(\chi_{15}^{2}, p\right.$-value $\left.=0.000\right)$, indicating a significant difference between correlates of aversion to own and others disadvantage. We find that gender does not affect either type of inequity aversion. Individuals with lowest levels of education have a higher level of inequity aversion, both when inequity is to their advantage (the joint test that all education coefficients are zero gives $p$-value $=0.0054$ ) or to their disadvantage (joint test with $p$-value $=0.0748$ ). While age does not have a significant effect on the disutility from own disadvantage, the disutility from other's disadvantage significantly increases with age. Individuals working for pay have significantly higher aversion than non-workers to inequity which is to their own disadvantage.

From (2), it is straightforward to break down the total variance in predicted log disutility from inequity into systematic parts $x^{\prime} \alpha$ and $x^{\prime} \beta$ explained by observed characteristics, and unobserved parts $u_{i}^{\alpha}$ and $u_{i}^{\beta}$. We find that $9.9 \%$ of the total variation in $\log (\alpha)$ and $17.6 \%$ of the total variation in $\log (\beta)$ can be attributed to variation in the systematic part.

The last two columns of Table 3 present estimates of the beliefs equation. We see that observable characteristics have statistically insignificant effects on beliefs. A Wald test of the null hypothesis that none of the observable characteristics plays a role gives 
a value of $22.94\left(\chi_{14}^{2}\right)$ with a $p$-value $=0.0613$, so that the null hypothesis is not rejected at the $5 \%$ level. This result is consistent with the fact that subjects with different observable characteristics had the same information set when we elicited their beliefs. They were randomly matched to another member of the panel, so that the proposer's characteristics are independent of the responder's characteristics. It is therefore perfectly rational that the proposer's own characteristics do not affect the beliefs on the responder's actions.

As expected from Figure 3, we find that corrections for framing effects are jointly significant. A Wald test $\left(\chi^{2}=169.2, p\right.$-value for $\left.8 \mathrm{df}=0.000\right)$ strongly rejects the null that there are no framing effects (i.e., $\phi_{1}=\phi_{2}=\ldots=\phi_{8}=0$ ).

Table 5 presents parameter estimates of the covariance structure of the parts of attitudes towards inequity aversion and subjective acceptance probabilities that are not explained by observed characteristics. We see that unobserved attitudes play a significant role, as reflected by the positive and precisely estimated variances of $u_{i}^{\alpha}, u_{i}^{\beta}$ and $u_{i}^{P}$. The share of total unexplained variation in beliefs of proposers in the ultimatum game explained by individual attitudes is $93.3 \% .{ }^{12}$ As conjectured, $u_{i}^{\alpha}$ and $u_{i}^{\beta}$ are significantly positively correlated, indicating that individuals with a stronger negative predisposition towards inequity to their disadvantage also tend to have a stronger negative predisposition towards inequity to their advantage. Interestingly, we find that the correlations of $u_{i}^{P}$ with $u_{i}^{\alpha}$ and $u_{i}^{\beta}$ are both significant and positive, implying that proposers in the ultimatum game who are optimistic about the acceptance rates of responders also tend to have significantly higher levels of inequity aversion, on average. Finally, the three scale parameters $\lambda^{U}, \lambda^{D}$ and $\lambda^{R}$, whose magnitudes are directly related to the $\mathrm{CP}$ units used in the experiment, are found to be precisely estimated in both models. All scale parameter estimates are larger in the rational expectations model than in the subjective beliefs model, indicating that incorporating subjective probabilities in the model reduces the estimated level of noise in the decision mak-

\footnotetext{
${ }^{12}$ Because $u_{i}^{P}$ and $\epsilon_{i j}^{P}$ are independent, the share of total unexplained variation in reported subjective probabilities attributed to attitudes is $V\left(u_{i}^{P}\right) /\left(V\left(u_{i}^{P}\right)+V\left(\epsilon_{i j}^{P}\right)\right)$.
} 
ing process. This particularly holds for $\lambda^{U}$, the parameter determining the noise in the decisions of proposers in the ultimatum game. The main difference between the two models is that these decisions depend on subjective beliefs in the complete model, whereas they depend on (objective) aggregate acceptance rates of responders in the rational expectations model. Apparently, at least part of what is ascribed to beliefs in the complete model is ascribed to noise in the model imposing rational and identical beliefs for all subjects. Furthermore, the covariance structure and scale parameters in the model using "raw" subjective probabilities as exogenous variables (bottom of Table 4) are similar to those of the model with corrects for endogeneity and framing bias in the reported subjective probabilities. In particular, there is still an important reduction in $\lambda^{U}$ relative to the model estimated assuming rational expectations.

\section{— Table 5 about here -}

\section{Distributions of $\alpha$ and $\beta$ and model specification}

The left hand columns of Table 6 presents quantiles of the predicted distributions of $\alpha_{i}$ and $\beta_{i}$ in the population based on parameter estimates of the complete model. The bottom of the table reports the estimated correlation coefficient between $\alpha_{i}$ and $\beta_{i}$ in the population. We find that the correlation between aversion for inequality to own and aversion towards inequality to other's disadvantage is positive.

\section{— Table 6 about here}

The quantiles give three important insights. First, the estimated proportion of pure selfish types is less than $10 \%$ of the population ( $\alpha$ and $\beta$ close to zero). ${ }^{13}$ Second, the cumulative distribution of $\beta$ rapidly dominates the cumulative distribution of $\alpha$, indicating a relatively stronger disutility from having more than others than from having

\footnotetext{
${ }^{13}$ Our functional form assumptions on $\alpha$ and $\beta$ rule out negative values. We also estimated a model where $\alpha$ and $\beta$ are linear functions of observable and unobservable characteristics. Results were very similar to those presented here.
} 
less than others. Third, there is considerable heterogeneity in predicted preferences for inequity aversion, with both $\alpha$ and $\beta$ taking values in excess of 4 .

Several papers provide point estimates of $\alpha$ and $\beta$, most of them based on experimental data collected in the lab with homogeneous samples (see, e.g., Goeree and Holt, 2000). To our knowledge, there exist no estimates of distributions of $\alpha$ and $\beta$ in either student or broader populations. In their original study of inequity aversion, Fehr and Schmidt (1999) proposed distributions of $\alpha$ and $\beta$ which were calibrated on experimental evidence based on observed offer and acceptance behavior from ultimatum experiments, mostly relying exclusively on student participants. Their calibrated multinomial distributions were as follows, with the first number denoting the value of $\alpha$ or $\beta$, and the number in parentheses denoting the calibrated proportion for that value in the population: $\alpha \in\{0(0.3), 0.5(0.3), 1(0.3), 4(0.1)\}$ and $\beta \in\{0(0.3), 0.25(0.3), 0.6(0.4)\} .{ }^{14}$ When comparing the medians of these distributions with the medians of $\alpha$ and $\beta$ in Figure 6, we find that the Dutch population tends to have inequity aversion parameters exceeding those of Fehr and Schmidt (1999). This is particularly the case for the distribution of $\beta$, where our estimated median is 1.227 , as opposed to 0.25 for the Fehr and Schmidt (1999) calibration. Moreover, more than $60 \%$ of our population is predicted to have an aversion for inequity to other's disadvantage with a $\beta$ greater than 1. In contrast, Fehr and Schmidt (1999) rule out the possibility that $\beta$ is larger than 1 as implausible, since values of $\beta$ which are greater than 1 suggest that subjects who have more than their opponent would, keeping the opponent's pay off constant, be better off giving away the surplus. Our responders data, characterized by an important share of plateau behavior, imply that, at least for a substantial part of the Dutch population, this is not as implausible as it seemed, with many people rejecting the offer and thus sacrificing their own pay-off to get more equity.

A natural question is whether the differences between our distributions of $\alpha$ and $\beta$ and those of Fehr and Schmidt (1999) can be explained by a specific cultural trait

\footnotetext{
${ }^{14}$ Similar distributions were found by Huck, Müller, and Norman (2001) in a sequential two player market experiment.
} 
of the Dutch population, or a composition effect, reflecting the greater heterogeneity of our participants compared to those of Fehr and Schmidt (1999). Restricting ourselves to only individuals below 25 years of age, with a university degree, who are not homemakers or working for pay, we get a median predicted $\alpha$ of 0.416 and a median predicted $\beta$ of 0.256 , well in line with the Fehr and Schmidt predictions. Hence, if there is a cultural effect, it does not show up in the subgroup of the population which mirrors the subjects typically used in lab experiments. These results suggest that the composition of a sample can have an important impact on the estimated levels of inequity aversion.

In order to check our model specification in an informal way, we estimated the vectors of inequity aversion parameters using only the accept/reject decisions of responders in the ultimatum game. This is based on equations (2), (6), and (7) only, and does not use the information on actions and beliefs of dictators and proposers in the ultimatum game. Using the new preference parameter estimates, we predicted again the population distributions of $\alpha$ and $\beta .{ }^{15}$ Quantiles of these distributions are presented along those of the complete model in the right hand columns of Table 6 . We find that both the quantiles and the correlation between the $\alpha$ and $\beta$ distributions accord well with those obtained when data on proposer decisions and beliefs are added to those of the responders.

\section{Marginal effects}

In order to quantify the relationship between the predicted heterogeneity in choice distributions and observable characteristics, we used the parameter estimates of the model with subjective expectations to compute expected choice distributions in the dictator and ultimatum games for a benchmark individual. Given the predominance of laboratory studies with subject pools recruited from the student body population, our benchmark subject is a female below 25 years of age and with a university degree

\footnotetext{
${ }^{15}$ Parameter estimates and significance levels were very close to those of the complete model and are available upon request.
} 
(Educ6 $=1$ ) who is currently neither working for pay, nor homemaker or retired (labor force status "Other"). We then computed corresponding distributions by altering the characteristics of the benchmark one at a time. Comparing the new predicted choice distributions with those of the benchmark individual gives a series of marginal effects for all the observable characteristics in the model.

Table 7 presents the results for the proposers in the dictator game ("dictators"). The mode of the baseline choice distribution of the benchmark dictator is to offer $0 \mathrm{CP}$, with a probability of $36.3 \%$. Offers of $150 \mathrm{CP}, 300 \mathrm{CP}$, and $450 \mathrm{CP}$ are made with probabilities of $19.6 \%, 14.1 \%$, and $20.8 \%$, respectively. The probability of making offers above 450 $\mathrm{CP}$ is less than $10 \%$. The other rows in the table present the deviations from the baseline probability resulting from altering one characteristic.

\section{— Table 7 about here -}

The strongest and most significant effects relate to changes in age and education level. We find that dictators with the lowest education level have a significantly higher probability of making offers in the equal split range, with the probability of making offers of $450 \mathrm{CP}$ and $550 \mathrm{CP} 15.3$ and 13.6 percentage points higher than for the highest level of education, respectively. Most of this increase in probability is taken from offers of $0 \mathrm{CP}$, whose probability falls by 21.3 percentage points. The magnitude of the effects tends to dampen as the level of education increases and comes closer to the benchmark level (high education). These education effects are consistent with the parameter estimates, showing that inequity aversion to other's disadvantage is stronger for low education than for high education individuals (see Table 3).

Similar differences are found across age groups. ${ }^{16}$ Individuals between 44 and 54 years of age have a 12.2 percentage points higher probability of offering $550 \mathrm{CP}$, and a 17.5 percentage points lower probability of offering $0 \mathrm{CP}$ than the younger benchmark person. The age effect is stronger as age differs more from the benchmark level. Individuals above 64 years of age have 21.1 percentage points higher probability of

\footnotetext{
${ }^{16}$ Age effects can be cohort effects as well as genuine age effects; the two cannot be distinguished here.
} 
offering $550 \mathrm{CP}$, and 25.6 percentage points lower probability of offering $0 \mathrm{CP}$. Again, these results reflect our finding that older subjects are more averse to inequity to other's disadvantage.

When computing marginal effects in the ultimatum game, account must be taken of the fact that variations in observable characteristics can affect the choice distribution through variations in preferences and variations in subjective beliefs. In order to make a direct comparison possible with the marginal effects in the dictator game (where all acceptance probabilities are equal to one), we present the marginal effects of shifts in preferences only, keeping the subjective beliefs fixed to those of the benchmark individual. The marginal effects reflecting differences in both subjective beliefs and preferences were found to be very similar, in accordance with the insignificant impact of observable characteristics on subjective beliefs reported in Table $3 .{ }^{17}$

Table 8 presents the results. To understand the difference with the dictator game, the first line reports the predicted subjective acceptance probabilities $Q_{i}(j)$ for the benchmark individual for all offers $j$. The benchmark individual's subjective probability that an offers of $0 \mathrm{CP}$ will be accepted is $12.2 \%$. This probability increase up to $58.0 \%$ for offers of $550 \mathrm{CP}$, and then decreases for higher offers. The low subjective acceptance probabilities for the low offers makes these alternatives unattractive, even to an expected payoff maximizer. Hence, despite having preferences which are relatively egoistic compared to those of other subgroups of the population, the benchmark proposer now has a predicted choice distribution exhibiting a high level of equity, with offers of $450 \mathrm{CP}$ occurring with a probability of $49.1 \%$. On the other hand, the benchmark probability of making offers of $0 \mathrm{CP}$ falls from $36.3 \%$ in the dictator game to $2.1 \%$ in the ultimatum game.

— Table 8 about here -

Overall, the marginal effects resemble those observed in the dictator game: older and less educated individuals more often make payoff equalizing offers of either 450 or

\footnotetext{
${ }^{17}$ Details are available upon request from the authors.
} 
550 CP. However, the magnitudes of the marginal effects are smaller in the ultimatum game than in the dictator game, and characterized by different patterns of substitution. While the probability mass going to 450 and $550 \mathrm{CP}$ is mostly taken from offers of 0 $\mathrm{CP}$ in the dictator game, it is taken from offers of $300 \mathrm{CP}$ in the ultimatum game, as the benchmark probability of making offers of $0 \mathrm{CP}$ is practically zero.

Table 9 presents the estimated marginal effects for responders in the ultimatum game, for each of the eight decisions of responders. Our benchmark has probabilities of above 80 percent of accepting offers of $450 \mathrm{CP}$ and above, showing that for the benchmark responders, threshold behavior is more prevalent than plateau behavior. In line with higher aversion to inequity to other's disadvantage, individuals with low levels of education, and those of 45 years and older have a lower probability than the benchmark of accepting offers that put them in a more advantageous position. For example, low educated individuals have a $29.5 \%$-points lower probability of accepting all of the $1000 \mathrm{CP}$, and those older than 64 years of age have a 39.6\%-points lower probability of accepting that same offer. These differences generate plateau behavior of the low educated and the elderly.

— Table 9 about here -

\section{Simulations}

In this section, we perform simulations to assess the goodness of fit of each model, enabling us to compare the predictive power of the model which uses data on subjective probabilities with the model estimated under the assumption that proposers in the ultimatum game have rational expectations. Figure 4 presents the observed (dark bars) and predicted (light bars) choice distributions for the three groups of players in our experiment. The left column presents the observed and predicted distributions based on the model using subjective probabilities of proposers in the ultimatum game while the right column presents the corresponding predictions for the model with rational expectations. All predicted distributions were computed by averaging predicted choice 
probabilities over all players in the relevant roles.

— Figure 4 about here -

We find that the model which incorporates the subjective data successfully predicts the important probability mass of proposals around the equal split, with some overprediction in the ultimatum game of proposals in the range between 0 and $300 \mathrm{CP}$. The fit is particularly good for the acceptance rates of responders, where the model captures the decline in acceptance rates for proposals over $550 \mathrm{CP}$. The rational expectations model provides a worse fit of the choice distribution of proposers in the ultimatum game. In particular, it predicts a more dispersed choice distribution, with more mass on low and high offers. As a result, it overpredicts the number of offers between 0 and $300 \mathrm{CP}$, underpredicts offers of $450 \mathrm{CP}$, underpredicts more offers of $550 \mathrm{CP}$, and clearly overpredicts offers in excess of $550 \mathrm{CP}$. Both models provide a similar fit to the choice distributions of proposers in the dictator game and to the acceptance probabilities of responders in the ultimatum game.

Figure 5 presents two predicted offer distributions computed using the estimates of the preference parameters of the model with subjective expectations data. The dark bars present the predicted offer distribution of this model. The light bars represent the predicted distribution after replacing the subjective acceptance rates of all proposers by "rational expectations," i.e., by the observed acceptance frequencies of responders in the data, taken from the bottom of Table 2. The predicted offer distribution under rational expectations is more concentrated around $450 \mathrm{CP}$ and $550 \mathrm{CP}$, reflecting the fact that observed acceptance rates of offers of $450 \mathrm{CP}$ and $550 \mathrm{CP}$ are above $90 \%$, while observed acceptance rates of offers below and above those amounts are substantially lower than the average subjective acceptance probabilities. The differences between the two distributions are substantial, emphasizing that deviations between subjective probabilities and rational expectations based probabilities have important consequences for decision making.

— Figure 5 about here - 
Finally, we present the simulated choice distributions according to the complete model with subjective expectations for four subgroups of the population: men below 25 years of age with a university degree and not working ("students", group 1), men below 25 years of age with a primary degree and not working (group 2), men above 64 years of age with a university degree and not working (group 3), and men above 64 years of age with a primary degree and not working (group 4). Results for proposers in the ultimatum game, proposers in the dictator game, and responders in the ultimatum game are presented in Figures 6, 7, and 8, respectively. In all figures, passing from the left to the right reduces education, while passing from the top to the bottom increases age. For proposers in the ultimatum and dictator games, we see that the predicted distribution in the subgroup which proxies the student population is concentrated towards offers between $0 \mathrm{CP}$ and $450 \mathrm{CP}$. In both games, individuals who are either older or less educated have a much greater tendency of making offers of $450 \mathrm{CP}$ or $550 \mathrm{CP}$, and a lower tendency of making offers below $450 \mathrm{CP}$. The difference increases when education as well as age are different from that of the student group (lower right hand side graph), with the likelihood of offers between $0 \mathrm{CP}$ and $300 \mathrm{CP}$ practically vanishing. The shifts in the dictator game are larger than in the ultimatum game, in line with the differences between the marginal effects in Tables 8 and 7 .

In Figure 8 with the acceptance probabilities of responders in the ultimatum game, all four subgroups have low probabilities of accepting offers of $0 \mathrm{CP}$ and $150 \mathrm{CP}$, and probabilities of accepting offers of $450 \mathrm{CP}$ and $550 \mathrm{CP}$ which exceed $80 \%$. Consistent with increasing aversion from inequity to the other player's disadvantage, the four graphs differ in terms of the acceptance probabilities of offers above $550 \mathrm{CP}$. While these remain above $80 \%$ in the student subgroup, they are much smaller for the less educated (group 2) and the older subgroups (group 3), with the probability of accepting all of the proposers endowment $(1000 \mathrm{CP})$ falling close to $40 \%$. Again, the decrease in the acceptance probabilities of high offers is stronger when combining the increase of age with the decrease of the education level, leading to group 4's quite high aversion for other's disadvantage and low acceptance rates for high offers. 
— Figures 6, 7, and 8 about here -

\section{Conclusion}

The ultimatum game and the dictator game are well-known tools in experimental economics for eliciting preferences for inequity aversion. The current paper improves on the empirical content of existing studies in several ways. First, a large representative sample of the (Dutch) population is used rather than the convenience sample of students used in most other studies. The size of the sample and its heterogeneity in terms of education level, age, gender, and other characteristics allow for an analysis of preference heterogeneity. Second, we randomly assign respondents to either the ultimatum or the dictator game, and to the role of proposer or responder, and use the random nature of this assignment to better identify the distribution of preferences (or "types") in the population. Third, we use direct questions on respondents' subjective probabilities that offers will be accepted or rejected to model respondents' beliefs and to test the assumption of rational expectations.

These features of the data are combined to formulate a structural micro-econometric model of preferences and beliefs, allowing for heterogeneity through observed and unobserved variables, and allowing for an arbitrary correlation structure of the unobserved heterogeneity components. The model is estimated combining all the available data and the findings are compared with a model that imposes that, for all amounts that can be proposed, each agent's beliefs are equal to the observed aggregate acceptance rates of responders ("rational expectations").

The main findings are as follows. First, the model is found to fit well the observed choices in our experiment. The model which uses subjective expectations fits the data better than a model which maintains that proposers in the ultimatum game have rational expectations, suggesting that collecting subjective expectations data may prove to be helpful in predicting behavior in many more experiments of proposal and response similar to the ones presented in this paper. The beliefs of proposers nevertheless 
showed a surprising amount of foresight in our heterogeneous population as they correctly forecasted the decline in acceptance rates for offers in excess of an equal split of the surplus. While the expected magnitude of the acceptance rates of these proposers differed substantially from the observed rates, they nevertheless correctly anticipated the presence of equity aversion in the responder population.

Second, there is substantial heterogeneity in preferences as well as beliefs. Inequity aversion rises with age and falls with education level, something that generates important variation in the choice distribution of dictators and responders in the ultimatum game. In particular, young, highly educated, and unemployed subjects make up the subgroup of the population whose decisions in the dictator games and responders in the ultimatum game are the most egoistic. Hence, extending the subject pool from students only to a more representative population not only increases the dispersion in predicted levels of inequity aversion, but also generates a distribution with much greater levels of inequity aversion. Indeed, the predicted distribution of aversion to own and other's disadvantage in our population is more dispersed than that which is usually derived from laboratory experiments (e.g. Fehr and Schmidt, 1999; Huck, Müller, and Normann, 2001). All this suggests that the choice of the subject pool may play an important role when making inferences about the distribution of preferences in the population.

Third, we found that variations in preferences have a much greater impact on the choice distribution in the dictator game than on the choice distribution in the ultimatum game. This is because in the latter, acceptance probabilities of low and high offers are much lower than acceptance probabilities of payoff equalizing offers, making the latter choices more attractive for a broader range of preferences.

Fourth, unobserved heterogeneity plays an important role for preferences as well as beliefs. The correlations between the heterogeneity terms indicate that the people who are more averse towards inequity at the cost of themselves are typically also more averse to inequity at the cost of the other player, and also tend to be relatively optimistic about the chances that responders will accept a given proposal. 
The fact that there is substantial (unobserved) heterogeneity of beliefs across the population already provides evidence that not everyone can have rational expectations, since every proposer is matched to a completely anonymous and random responder. Moreover, we find that even the median proposer does not have rational expectations, and underestimates the probability that amounts sent exceeding the equal split will be accepted by the responder. The deviations from rational expectations lead to a substantial dispersion in the proposed amounts.

Future research can address various limitations. One is extending the number of "types" of players with different preferences. We already allow for a continuum of types with two inequity aversion parameters varying from zero to infinity, but extensions could, for example, allow for maxmin preferences (e.g., Charness and Rabin, 2002), which will typically require additional experimental data. Another important extension is to consider the effect of intentions (see e.g., Blount, 1995) which could be analyzed by comparing the current data with similar data where the proposer is replaced by a computer generating the amount offered, taking away the argument that different offers are informative of the intentions of proposers. 


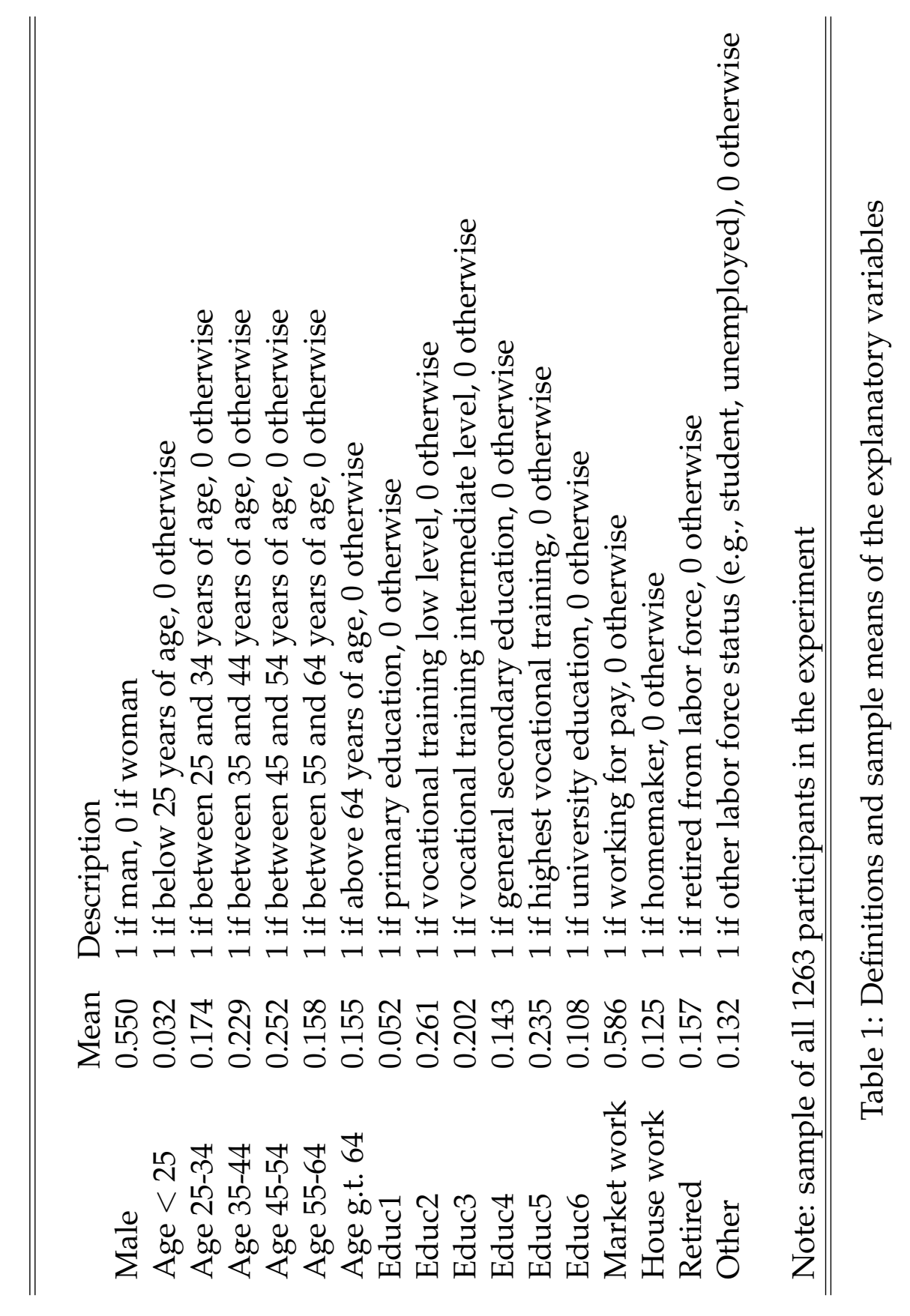




\begin{tabular}{lcccccccc}
0 & 150 & 300 & 450 & 550 & 700 & 850 & 1000 & $\mathrm{~N}$ \\
& \multicolumn{7}{c}{ Threshold behavior } \\
1 & 1 & 1 & 1 & 1 & 1 & 1 & 1 & 17 \\
0 & 1 & 1 & 1 & 1 & 1 & 1 & 1 & 28 \\
0 & 0 & 1 & 1 & 1 & 1 & 1 & 1 & 30 \\
0 & 0 & 0 & 1 & 1 & 1 & 1 & 1 & 89 \\
0 & 0 & 0 & 0 & 1 & 1 & 1 & 1 & 12 \\
0 & 0 & 0 & 0 & 0 & 0 & 0 & 1 & 1 \\
1 & 1 & 1 & 1 & 0 & 0 & 0 & 0 & 1 \\
1 & 1 & 1 & 1 & 1 & 0 & 0 & 0 & 1 \\
1 & 0 & 0 & 0 & 0 & 0 & 0 & 0 & 1
\end{tabular}

\section{Plateau behavior}

$\begin{array}{lllllllll}0 & 0 & 0 & 1 & 1 & 1 & 0 & 0 & 20 \\ 0 & 0 & 0 & 1 & 0 & 0 & 0 & 0 & 22 \\ 0 & 0 & 0 & 1 & 1 & 0 & 0 & 0 & 61 \\ 0 & 0 & 0 & 1 & 1 & 1 & 1 & 0 & 6 \\ 0 & 0 & 1 & 1 & 1 & 0 & 0 & 0 & 8 \\ 0 & 0 & 0 & 0 & 1 & 0 & 0 & 0 & 7 \\ 0 & 0 & 1 & 1 & 0 & 0 & 0 & 0 & 2 \\ 0 & 1 & 1 & 1 & 1 & 1 & 1 & 0 & 4 \\ 0 & 0 & 1 & 1 & 1 & 1 & 0 & 0 & 11 \\ 0 & 0 & 0 & 0 & 1 & 1 & 0 & 0 & 1 \\ 0 & 0 & 0 & 0 & 0 & 1 & 0 & 0 & 1 \\ 0 & 1 & 1 & 1 & 0 & 0 & 0 & 0 & 1 \\ 0 & 0 & 1 & 1 & 1 & 1 & 1 & 0 & 1\end{array}$

\section{Chainsaw behavior}

$\begin{array}{lllllllll}0 & 1 & 0 & 1 & 1 & 1 & 1 & 1 & 1 \\ 1 & 0 & 0 & 0 & 1 & 1 & 1 & 1 & 1 \\ 1 & 0 & 1 & 1 & 0 & 1 & 0 & 0 & 1 \\ 0 & 1 & 0 & 1 & 1 & 1 & 0 & 0 & 1 \\ 1 & 1 & 0 & 1 & 1 & 1 & 0 & 0 & 1 \\ 1 & 0 & 0 & 1 & 1 & 1 & 1 & 1 & 1 \\ 0 & 0 & 0 & 1 & 1 & 0 & 0 & 1 & 1 \\ 0 & 0 & 0 & 0 & 1 & 0 & 0 & 1 & 1 \\ 0 & 1 & 1 & 1 & 1 & 1 & 0 & 1 & 1 \\ 1 & 0 & 0 & 0 & 1 & 0 & 0 & 0 & 1\end{array}$

Aggregate acceptance rates

$\begin{array}{llllllll}0.05 & 0.15 & 0.32 & 0.93 & 0.91 & 0.68 & 0.58 & 0.55\end{array}$

Notes: Sample of 355 responders in the ultimatum game. Columns: amounts that can be offered (strategy method). 1: accept offer; 0: reject offer; $\mathrm{N}$ : number of observations.

Table 2: Observed choice sequences for responders 


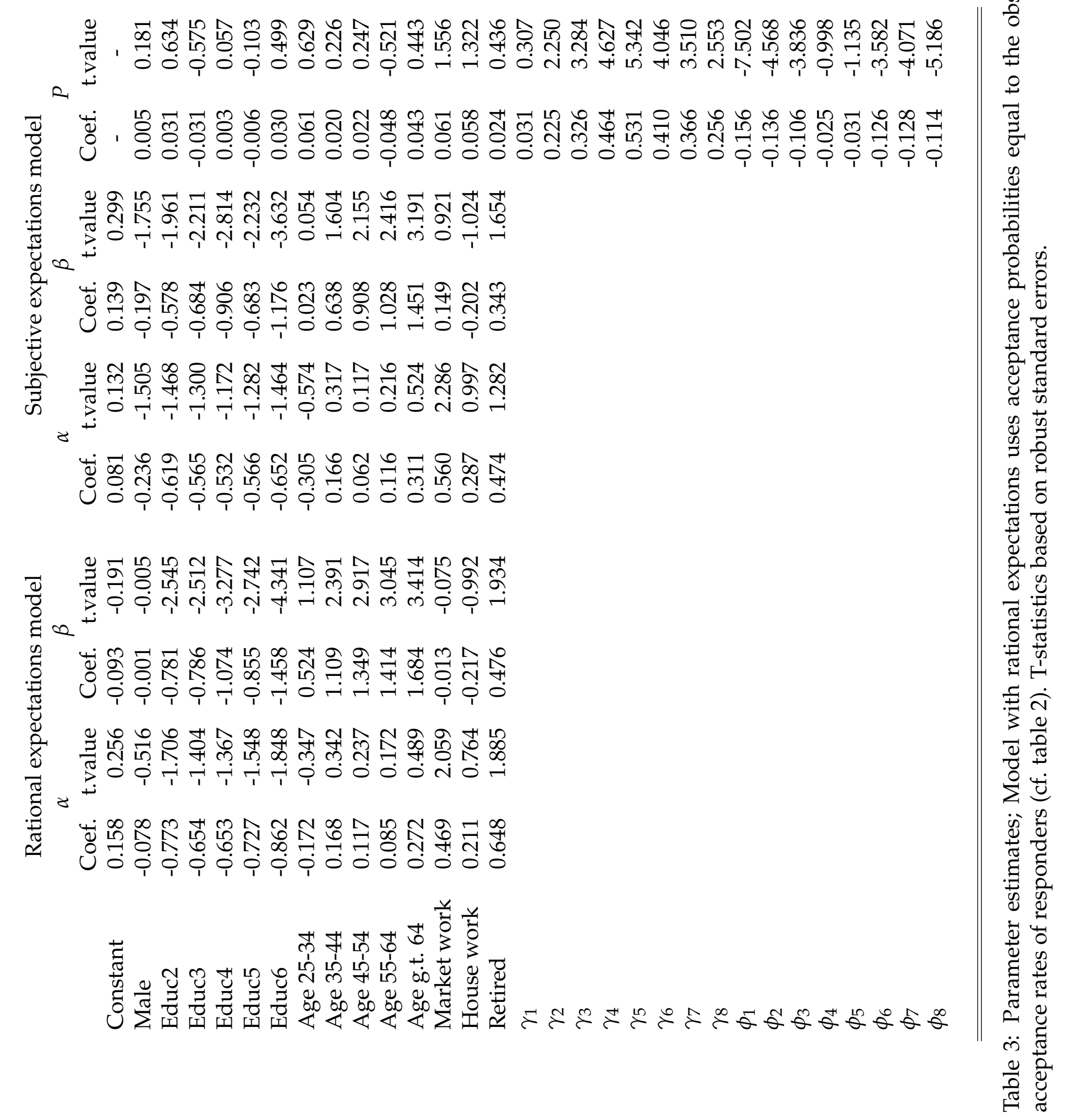


$\alpha \quad \beta$

\begin{tabular}{lcccc} 
& \multicolumn{2}{c}{$\alpha$} & \multicolumn{2}{c}{$\beta$} \\
Constant & Coef. & t.value & Coef. & t.value \\
Male & 0.233 & 0.391 & 0.188 & 0.506 \\
Educ2 & -0.167 & -1.141 & -0.143 & -1.412 \\
Educ3 & -0.777 & -1.791 & -0.665 & -2.582 \\
Educ4 & -0.785 & -1.772 & -0.812 & -3.071 \\
Educ5 & -0.696 & -1.528 & -0.986 & -3.635 \\
Educ6 & -0.704 & -1.568 & -0.772 & -2.921 \\
Age 25-34 & -0.885 & -1.984 & -1.331 & -4.734 \\
Age 35-44 & -0.099 & -0.198 & 0.352 & 1.041 \\
Age 45-54 & 0.310 & 0.628 & 0.824 & 2.486 \\
Age 55-64 & 0.116 & 0.234 & 1.112 & 3.346 \\
Age g.t. 64 & 0.154 & 0.310 & 1.168 & 3.478 \\
Market work & 0.277 & 0.501 & 1.133 & 3.692 \\
House work & 0.466 & 2.054 & 0.037 & 0.268 \\
Retired & 0.234 & 0.856 & -0.195 & -1.077 \\
& 0.556 & 1.629 & 0.507 & 2.505
\end{tabular}

Covariance matrix and scale parameters

\begin{tabular}{lll} 
& Coef. & t.value \\
$V\left(u_{i}^{\alpha}\right)$ & 0.842 & 6.587 \\
$V\left(u_{i}^{\beta}\right)$ & 1.259 & 7.689 \\
$\operatorname{Corr}\left(u_{i}^{\alpha}, u_{i}^{\beta}\right)$ & 0.282 & 4.011 \\
$\lambda^{U}$ & 55.983 & 15.128 \\
$\lambda^{D}$ & 154.934 & 8.849 \\
$\lambda^{R}$ & 70.527 & 12.936 \\
\hline \hline
\end{tabular}

Table 4: Parameter estimates of model using raw subjective expectations data. T-values based on robust standard errors. 


\begin{tabular}{|c|c|c|c|c|}
\hline \multirow[b]{3}{*}{$V\left(u_{i}^{\alpha}\right)$} & \multicolumn{2}{|c|}{ Rational expectations model } & \multicolumn{2}{|c|}{ Subjective expectations model } \\
\hline & Coef. & t.value & Coef. & t.value \\
\hline & 1.017 & 6.356 & 0.803 & 6.137 \\
\hline$V\left(u_{i}^{\beta}\right)$ & 1.144 & 8.171 & 1.331 & 7.273 \\
\hline$V\left(u_{i}^{P}\right)$ & - & - & 0.851 & 8.343 \\
\hline $\operatorname{Corr}\left(u_{i}^{\alpha}, u_{i}^{\beta}\right)$ & 0.255 & 3.899 & 0.251 & 3.777 \\
\hline $\operatorname{Corr}\left(u_{i}^{\alpha}, u_{i}^{P}\right)$ & - & - & 0.835 & 7.813 \\
\hline $\operatorname{Corr}\left(u_{i}^{\beta}, u_{i}^{P}\right)$ & - & - & 0.625 & 3.173 \\
\hline$\lambda^{U}$ & 115.64 & 11.325 & 45.513 & 12.254 \\
\hline$\lambda^{D}$ & 161.09 & 9.998 & 155.555 & 8.620 \\
\hline$\lambda^{R}$ & 72.04 & 10.857 & 68.167 & 11.976 \\
\hline$V\left(\epsilon_{i j}^{P}\right)$ & - & - & 0.061 & 37.043 \\
\hline
\end{tabular}

Table 5: Estimates of the covariance matrix and scale parameters. T-values based on robust standard errors.

\begin{tabular}{lcccc}
\hline \hline & \multicolumn{3}{c}{ Prop. and Resp. } & \multicolumn{2}{c}{ Resp only } \\
Percentile & $\alpha$ & $\beta$ & $\alpha$ & $\beta$ \\
10th & 0.187 & 0.329 & 0.207 & 0.346 \\
20th & 0.322 & 0.514 & 0.346 & 0.468 \\
30th & 0.472 & 0.713 & 0.506 & 0.603 \\
40th & 0.657 & 0.943 & 0.696 & 0.963 \\
50th & 0.898 & 1.227 & 0.928 & 1.231 \\
60th & 1.225 & 1.589 & 1.246 & 1.732 \\
70th & 1.696 & 2.088 & 1.717 & 1.969 \\
80th & 2.482 & 2.897 & 2.475 & 2.975 \\
90th & 4.268 & 4.499 & 4.185 & 4.784 \\
& & & & \\
Correlation & \multicolumn{2}{c}{0.267} & & \\
& \multicolumn{5}{c}{0.241} \\
\hline \hline
\end{tabular}

Table 6: Sample percentiles of the estimated distributions of $\alpha$ and $\beta$ based on parameter estimates from the complete model combining both proposers and responders data (columns 2 and 3) and a model using only responders (columns 4 and 5). 


\begin{tabular}{|c|c|c|c|c|c|c|c|c|}
\hline & $0 \mathrm{CP}$ & $150 \mathrm{CP}$ & $300 \mathrm{CP}$ & $450 \mathrm{CP}$ & $550 \mathrm{CP}$ & $700 \mathrm{CP}$ & $850 \mathrm{CP}$ & $1000 \mathrm{CP}$ \\
\hline Baseline prob. & 0.363 & 0.196 & 0.141 & 0.208 & 0.078 & 0.011 & 0.003 & 0.001 \\
\hline \multirow[t]{2}{*}{ Male } & $-0.032^{* *}$ & -0.007 & 0.004 & $0.023^{* *}$ & $0.011^{* *}$ & 0.001 & 0.000 & 0.000 \\
\hline & $(0.015)$ & $(0.007)$ & $(0.007)$ & $(0.012)$ & $(0.005)$ & $(0.001)$ & $(0.000)$ & $(0.000)$ \\
\hline \multirow[t]{2}{*}{ Educ1 } & $-0.213^{* *}$ & $-0.080^{* * *}$ & -0.012 & $0.153^{* * *}$ & $0.136^{* * *}$ & $0.013^{* * *}$ & $0.002^{* * *}$ & $0.001^{* * *}$ \\
\hline & $(0.092)$ & $(0.027)$ & $(0.042)$ & $(0.054)$ & $(0.019)$ & $(0.003)$ & $(0.000)$ & $(0.000)$ \\
\hline \multirow[t]{2}{*}{ Educ2 } & $-0.107^{* * *}$ & $-0.033^{*}$ & 0.000 & $0.057^{*}$ & $0.069^{* * *}$ & $0.010^{* * *}$ & $0.002^{* * *}$ & $0.001^{* * *}$ \\
\hline & $(0.041)$ & (0.019) & $(0.023)$ & $(0.034)$ & $(0.018)$ & $(0.002)$ & $(0.001)$ & $(0.000)$ \\
\hline \multirow[t]{2}{*}{ Educ3 } & $-0.084^{* * *}$ & -0.027 & -0.000 & $0.054^{* * *}$ & $0.049 * * *$ & $0.007^{* * *}$ & $0.001^{* * *}$ & $0.000^{* * *}$ \\
\hline & $(0.025)$ & (0.017) & (0.019) & $(0.018)$ & $(0.015)$ & $(0.002)$ & $(0.000)$ & $(0.000)$ \\
\hline \multirow[t]{2}{*}{ Educ4 } & $-0.044^{* * *}$ & -0.013 & 0.002 & $0.030^{* *}$ & $0.022^{* * *}$ & $0.003^{* * *}$ & $0.001^{* * *}$ & $0.000^{* *}$ \\
\hline & $(0.014)$ & $(0.010)$ & (0.010) & $(0.012)$ & $(0.008)$ & $(0.001)$ & $(0.000)$ & $(0.000)$ \\
\hline \multirow[t]{2}{*}{ Educ5 } & $-0.083^{* * *}$ & -0.028 & -0.002 & $0.059 * * *$ & $0.046^{* * *}$ & $0.006^{* *}$ & $0.001^{* *}$ & $0.000^{* *}$ \\
\hline & $(0.022)$ & $(0.018)$ & (0.019) & $(0.017)$ & $(0.016)$ & $(0.002)$ & $(0.001)$ & $(0.000)$ \\
\hline \multirow[t]{2}{*}{ Age $25-34$} & -0.009 & 0.010 & 0.009 & -0.032 & 0.014 & 0.006 & 0.002 & 0.001 \\
\hline & $(0.067)$ & $(0.023)$ & (0.015) & $(0.082)$ & $(0.016)$ & $(0.004)$ & $(0.002)$ & $(0.001)$ \\
\hline \multirow[t]{2}{*}{ Age $35-44$} & -0.123 & -0.033 & 0.007 & 0.061 & $0.073^{* * *}$ & $0.011^{* * *}$ & $0.003^{* * *}$ & $0.001^{*}$ \\
\hline & $(0.075)$ & $(0.020)$ & $(0.026)$ & $(0.067)$ & $(0.011)$ & $(0.002)$ & $(0.001)$ & $(0.000)$ \\
\hline \multirow[t]{2}{*}{ Age $45-54$} & $-0.175^{*}$ & $-0.058^{* *}$ & -0.003 & 0.090 & $0.122^{* * *}$ & $0.019^{* * *}$ & $0.004^{* * *}$ & $0.001^{* * *}$ \\
\hline & $(0.090)$ & $(0.025)$ & $(0.034)$ & $(0.067)$ & $(0.018)$ & $(0.003)$ & $(0.001)$ & $(0.000)$ \\
\hline \multirow[t]{2}{*}{ Age 55-64 } & $-0.195^{* *}$ & $-0.069^{* * *}$ & -0.008 & 0.104 & $0.141^{* * *}$ & $0.020^{* * *}$ & $0.005^{* * *}$ & $0.001^{* * *}$ \\
\hline & $(0.092)$ & $(0.025)$ & (0.037) & $(0.064)$ & $(0.016)$ & $(0.003)$ & $(0.001)$ & $(0.000)$ \\
\hline \multirow[t]{2}{*}{ Age g.t. 64} & $-0.256^{* *}$ & $-0.107^{* * *}$ & -0.033 & $0.151^{* * *}$ & $0.212^{* * *}$ & $0.026^{* * *}$ & $0.005^{* * *}$ & $0.001^{* * *}$ \\
\hline & $(0.109)$ & $(0.030)$ & $(0.048)$ & $(0.047)$ & $(0.035)$ & $(0.009)$ & $(0.002)$ & $(0.000)$ \\
\hline \multirow[t]{2}{*}{ Market work } & -0.023 & 0.003 & 0.011 & 0.014 & -0.002 & -0.002 & -0.001 & -0.000 \\
\hline & $(0.037)$ & $(0.011)$ & $(0.007)$ & $(0.034)$ & $(0.011)$ & $(0.002)$ & $(0.001)$ & $(0.000)$ \\
\hline \multirow[t]{2}{*}{ House work } & $0.034^{* *}$ & 0.014 & 0.003 & -0.025 & -0.021 & $-0.003^{*}$ & $-0.001^{*}$ & $-0.000^{*}$ \\
\hline & $(0.014)$ & $(0.011)$ & (0.009) & (0.019) & $(0.013)$ & $(0.002)$ & $(0.000)$ & $(0.000)$ \\
\hline \multirow[t]{2}{*}{ Retired } & -0.061 & -0.010 & 0.011 & 0.033 & $0.025^{* *}$ & 0.002 & 0.000 & 0.000 \\
\hline & (0.047) & (0.013) & $(0.015)$ & (0.049) & $(0.012)$ & $(0.003)$ & $(0.001)$ & (0.000) \\
\hline
\end{tabular}

'*': significant at 10 percent level.

${ }^{\prime * * \prime}$ : significant at 5 percent level.

'***': significant at 1 percent level.

Standard errors in parentheses.

Table 7: Marginal effects for dictators based on model with subjective expectations. Baseline choice probability levels represent probabilities for a female, with the highest level of education (Educ6), younger than 25 years, labor force status "Other". Effects are computed as differences in the choice probabilities compared to the baseline probability. Standard errors in parentheses. 


\begin{tabular}{|c|c|c|c|c|c|c|c|c|}
\hline & $0 \mathrm{CP}$ & $150 \mathrm{CP}$ & $300 \mathrm{CP}$ & $450 \mathrm{CP}$ & $550 \mathrm{CP}$ & $700 \mathrm{CP}$ & $850 \mathrm{CP}$ & $1000 \mathrm{CP}$ \\
\hline Baseline $Q(j)$ & 0.122 & 0.279 & 0.380 & 0.514 & 0.580 & 0.456 & 0.421 & 0.311 \\
\hline Baseline prob. & 0.021 & 0.084 & 0.157 & 0.491 & 0.218 & 0.014 & 0.007 & 0.008 \\
\hline \multirow[t]{2}{*}{ Male } & 0.000 & -0.009 & $-0.010^{* *}$ & 0.016 & 0.004 & -0.001 & -0.000 & -0.000 \\
\hline & $(0.001)$ & $(0.007)$ & $(0.004)$ & $(0.014)$ & $(0.007)$ & $(0.001)$ & $(0.000)$ & $(0.000)$ \\
\hline \multirow[t]{2}{*}{ Educ1 } & 0.007 & -0.049 & $-0.078^{* *}$ & 0.011 & $0.109^{* * *}$ & -0.000 & -0.000 & 0.000 \\
\hline & (0.015) & $(0.037)$ & $(0.032)$ & $(0.071)$ & $(0.017)$ & $(0.001)$ & $(0.000)$ & $(0.001)$ \\
\hline \multirow[t]{2}{*}{ Educ2 } & 0.000 & -0.029 & $-0.042^{* * *}$ & -0.011 & $0.078^{* * *}$ & 0.002 & 0.000 & 0.000 \\
\hline & (0.004) & (0.019) & $(0.013)$ & $(0.050)$ & $(0.017)$ & $(0.001)$ & $(0.000)$ & $(0.000)$ \\
\hline \multirow[t]{2}{*}{ Educ3 } & 0.002 & $-0.022^{*}$ & $-0.032^{* * *}$ & -0.000 & $0.051^{* * *}$ & $0.001^{* *}$ & 0.000 & 0.000 \\
\hline & (0.006) & $(0.013)$ & $(0.009)$ & $(0.033)$ & $(0.012)$ & $(0.000)$ & $(0.000)$ & (0.000) \\
\hline \multirow[t]{2}{*}{ Educ4 } & 0.001 & $-0.012^{*}$ & $-0.016^{* * *}$ & 0.007 & $0.020^{* * *}$ & 0.000 & -0.000 & 0.000 \\
\hline & $(0.004)$ & $(0.007)$ & $(0.004)$ & (0.017) & $(0.007)$ & $(0.000)$ & $(0.000)$ & $(0.000)$ \\
\hline \multirow[t]{2}{*}{ Educ5 } & 0.003 & $-0.021^{*}$ & $-0.031^{* * *}$ & 0.002 & $0.046^{* * *}$ & 0.001 & 0.000 & 0.000 \\
\hline & (0.009) & $(0.011)$ & $(0.008)$ & $(0.024)$ & $(0.012)$ & $(0.000)$ & $(0.000)$ & $(0.000)$ \\
\hline \multirow[t]{2}{*}{ Age 25-34 } & -0.006 & -0.011 & -0.010 & -0.026 & 0.049 & 0.004 & 0.001 & -0.001 \\
\hline & $(0.012)$ & $(0.019)$ & $(0.020)$ & $(0.064)$ & $(0.040)$ & $(0.004)$ & $(0.001)$ & $(0.001)$ \\
\hline \multirow[t]{2}{*}{ Age 35-44 } & -0.003 & -0.034 & $-0.047^{*}$ & 0.000 & $0.082^{* * *}$ & 0.002 & 0.000 & -0.000 \\
\hline & (0.005) & $(0.028)$ & $(0.026)$ & (0.069) & $(0.022)$ & (0.003) & $(0.001)$ & $(0.001)$ \\
\hline \multirow[t]{2}{*}{ Age 45-54 } & -0.001 & -0.045 & $-0.068^{* *}$ & -0.027 & $0.136^{* * *}$ & $0.003^{*}$ & 0.001 & 0.000 \\
\hline & (0.005) & $(0.034)$ & $(0.033)$ & $(0.074)$ & $(0.020)$ & (0.002) & $(0.001)$ & (0.001) \\
\hline \multirow[t]{2}{*}{ Age 55-64 } & 0.001 & -0.048 & $-0.075^{* *}$ & -0.033 & $0.151^{* * *}$ & $0.003^{* *}$ & 0.001 & 0.000 \\
\hline & (0.007) & $(0.035)$ & $(0.033)$ & $(0.075)$ & $(0.012)$ & $(0.002)$ & $(0.000)$ & (0.000) \\
\hline \multirow[t]{2}{*}{ Age g.t. 64} & 0.011 & -0.057 & $-0.099 * *$ & -0.061 & $0.201^{* * *}$ & $0.003^{* *}$ & $0.000^{* * *}$ & 0.001 \\
\hline & $(0.022)$ & $(0.042)$ & $(0.041)$ & $(0.070)$ & $(0.046)$ & $(0.001)$ & $(0.000)$ & $(0.001)$ \\
\hline \multirow[t]{2}{*}{ Market work } & -0.002 & -0.008 & -0.003 & $0.039^{*}$ & -0.023 & -0.002 & -0.001 & -0.000 \\
\hline & (0.005) & $(0.013)$ & $(0.011)$ & $(0.023)$ & $(0.018)$ & $(0.002)$ & $(0.000)$ & $(0.000)$ \\
\hline \multirow[t]{2}{*}{ House work } & -0.002 & $0.009 * * *$ & $0.016^{* * *}$ & 0.012 & $-0.033^{* *}$ & $-0.002^{*}$ & $-0.000^{* *}$ & -0.000 \\
\hline & $(0.006)$ & $(0.003)$ & $(0.005)$ & $(0.011)$ & $(0.014)$ & (0.001) & $(0.000)$ & (0.000) \\
\hline \multirow[t]{2}{*}{ Retired } & -0.002 & -0.018 & -0.019 & 0.030 & 0.011 & -0.001 & -0.000 & -0.000 \\
\hline & (0.005) & (0.018) & (0.013) & $(0.050)$ & $(0.030)$ & $(0.003)$ & $(0.001)$ & $(0.001)$ \\
\hline
\end{tabular}

'*': significant at 10 percent level.

${ }^{\prime * * \prime}$ : significant at 5 percent level.

'***': significant at 1 percent level.

Standard errors in parentheses.

Table 8: Marginal effects for proposers in the ultimatum game keeping beliefs at the baseline level. Baseline choice probability levels represent probabilities for a female, with the highest level of education (Educ6), younger than 25 years, labor force status "Other". Effects are computed as differences in the choice probabilities compared to the baseline probability. Standard errors in parentheses. 


\begin{tabular}{|c|c|c|c|c|c|c|c|c|}
\hline & $0 \mathrm{CP}$ & $150 \mathrm{CP}$ & $300 \mathrm{CP}$ & $450 \mathrm{CP}$ & $550 \mathrm{CP}$ & $700 \mathrm{CP}$ & $850 \mathrm{CP}$ & $1000 \mathrm{CP}$ \\
\hline Baseline prob. & 0.088 & 0.333 & 0.600 & 0.880 & 0.985 & 0.915 & 0.867 & 0.835 \\
\hline \multirow{2}{*}{ Male } & -0.022 & -0.050 & -0.041 & -0.009 & -0.002 & -0.015 & -0.022 & -0.027 \\
\hline & $(0.023)$ & $(0.037)$ & $(0.028)$ & (0.013) & $(0.005)$ & $(0.014)$ & $(0.017)$ & (0.019) \\
\hline \multirow[t]{2}{*}{ Educ1 } & -0.055 & -0.145 & -0.134 & -0.031 & -0.045 & $-0.190^{* *}$ & $-0.258^{* * *}$ & $-0.295^{* * *}$ \\
\hline & $(0.060)$ & (0.119) & $(0.087)$ & $(0.040)$ & $(0.048)$ & $(0.085)$ & $(0.093)$ & $(0.096)$ \\
\hline \multirow[t]{2}{*}{ Educ2 } & -0.014 & -0.020 & 0.006 & 0.023 & -0.012 & -0.066 & $-0.094^{*}$ & $-0.113^{* *}$ \\
\hline & $(0.026)$ & $(0.044)$ & $(0.040)$ & $(0.043)$ & $(0.017)$ & $(0.043)$ & $(0.050)$ & $(0.055)$ \\
\hline \multirow[t]{2}{*}{ Educ3 } & -0.012 & -0.022 & -0.011 & 0.004 & -0.013 & -0.058 & -0.080 & $-0.094^{*}$ \\
\hline & (0.015) & $(0.024)$ & $(0.018)$ & (0.017) & $(0.021)$ & $(0.047)$ & $(0.050)$ & $(0.054)$ \\
\hline \multirow[t]{2}{*}{ Educ4 } & -0.013 & -0.026 & -0.019 & -0.002 & -0.006 & -0.028 & -0.039 & -0.047 \\
\hline & (0.015) & $(0.023)$ & (0.017) & (0.013) & $(0.011)$ & $(0.026)$ & $(0.027)$ & $(0.030)$ \\
\hline \multirow[t]{2}{*}{ Educ5 } & -0.006 & $-0.015^{*}$ & $-0.016^{*}$ & -0.008 & -0.016 & -0.065 & -0.086 & -0.100 \\
\hline & (0.006) & $(0.009)$ & (0.009) & $(0.011)$ & $(0.027)$ & $(0.056)$ & $(0.058)$ & $(0.061)$ \\
\hline \multirow[t]{2}{*}{ Age 25-34 } & -0.003 & 0.030 & 0.100 & 0.078 & 0.012 & 0.041 & 0.048 & 0.049 \\
\hline & (0.053) & (0.110) & $(0.126)$ & $(0.120)$ & $(0.031)$ & $(0.073)$ & (0.098) & (0.109) \\
\hline \multirow[t]{2}{*}{ Age 35-44 } & -0.034 & -0.066 & -0.015 & 0.038 & -0.002 & -0.050 & -0.083 & $-0.105^{*}$ \\
\hline & (0.057) & (0.113) & (0.095) & $(0.084)$ & $(0.012)$ & $(0.049)$ & $(0.057)$ & $(0.061)$ \\
\hline \multirow[t]{2}{*}{ Age $45-54$} & -0.024 & -0.037 & 0.007 & 0.037 & -0.016 & $-0.109^{*}$ & $-0.161^{* *}$ & $-0.195^{* *}$ \\
\hline & $(0.044)$ & $(0.081)$ & $(0.072)$ & (0.073) & $(0.021)$ & $(0.057)$ & $(0.066)$ & $(0.076)$ \\
\hline \multirow[t]{2}{*}{ Age 55-64 } & -0.026 & -0.045 & -0.007 & 0.029 & -0.027 & $-0.143^{* *}$ & $-0.204^{* * *}$ & $-0.240^{* * *}$ \\
\hline & $(0.042)$ & $(0.076)$ & $(0.064)$ & $(0.062)$ & $(0.030)$ & $(0.062)$ & $(0.074)$ & $(0.083)$ \\
\hline \multirow[t]{2}{*}{ Age g.t. 64} & -0.028 & -0.065 & -0.056 & -0.014 & -0.078 & $-0.278^{* *}$ & $-0.357^{* * *}$ & $-0.396^{* * *}$ \\
\hline & $(0.030)$ & (0.048) & $(0.036)$ & $(0.022)$ & $(0.073)$ & $(0.115)$ & $(0.112)$ & $(0.108)$ \\
\hline \multirow[t]{2}{*}{ Market work } & -0.051 & -0.129 & -0.111 & -0.020 & 0.006 & 0.010 & 0.007 & 0.003 \\
\hline & $(0.057)$ & (0.110) & $(0.080)$ & (0.038) & $(0.015)$ & $(0.034)$ & $(0.046)$ & $(0.048)$ \\
\hline \multirow[t]{2}{*}{ House work } & -0.027 & -0.062 & -0.051 & -0.010 & 0.008 & 0.030 & 0.039 & 0.043 \\
\hline & $(0.029)$ & $(0.048)$ & $(0.036)$ & (0.019) & (0.019) & $(0.040)$ & $(0.045)$ & $(0.043)$ \\
\hline \multirow[t]{2}{*}{ Retired } & -0.052 & -0.128 & -0.092 & 0.008 & 0.002 & -0.013 & -0.026 & -0.036 \\
\hline & $(0.067)$ & $(0.141)$ & $(0.110)$ & $(0.070)$ & (0.009) & $(0.030)$ & $(0.044)$ & $(0.047)$ \\
\hline
\end{tabular}

${ }^{\prime *}$ : significant at 10 percent level.

${ }^{\prime * * \prime}$ : significant at 5 percent level.

'***': significant at 1 percent level.

Standard errors in parentheses.

Table 9: Marginal effects for responders in the ultimatum game based on model with subjective expectations. Baseline probabilities of acceptance represent probabilities for a female, with the highest level of education (Educ6), younger than 25 years, labor force status "other". Effects are computed as differences in the choice probabilities compared to the baseline probability. Standard errors in parentheses. 


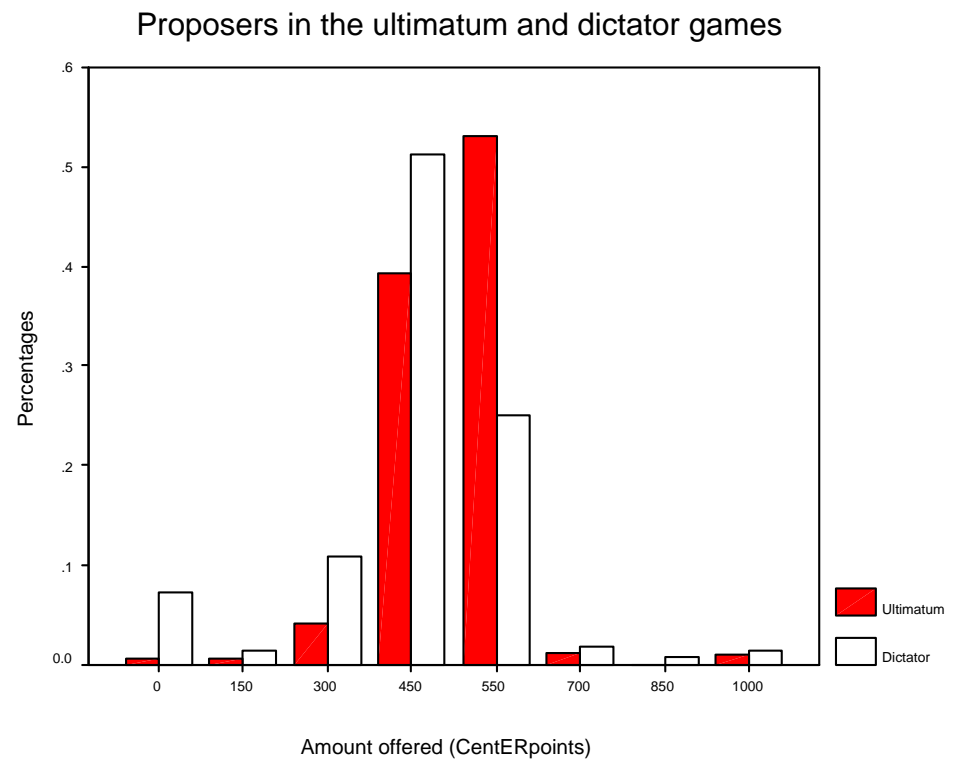

Figure 1: Distribution of amounts sent in the dictator and ultimatum games 
Subjective acceptance probabilities

Offers of 0 CentERpoints

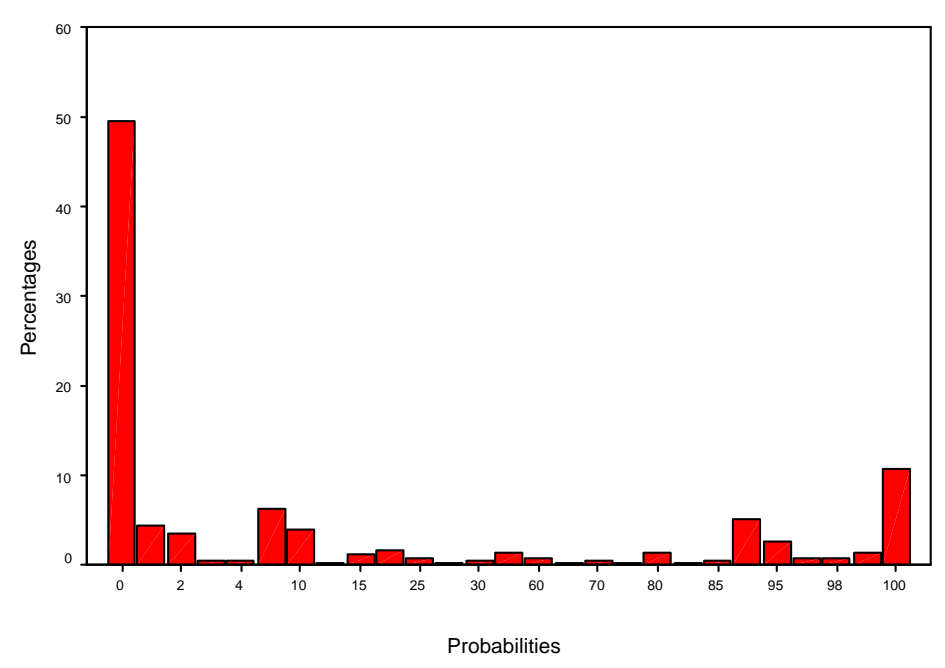

Subjective acceptance probabilities

Offers of 450 CentERpoints

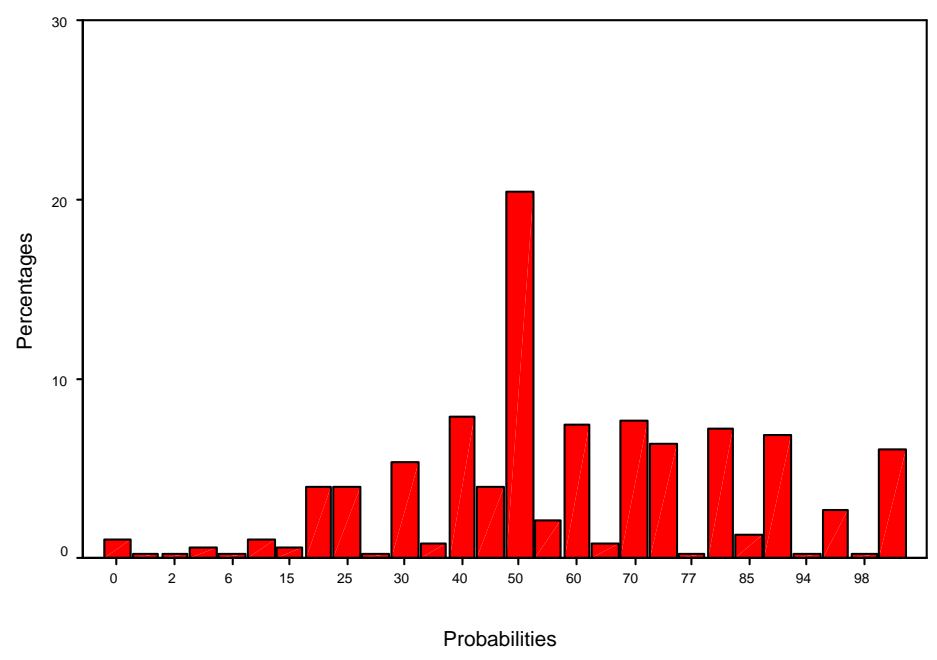

Subjective acceptance probabilities

Offers of 1000 CentERpoints

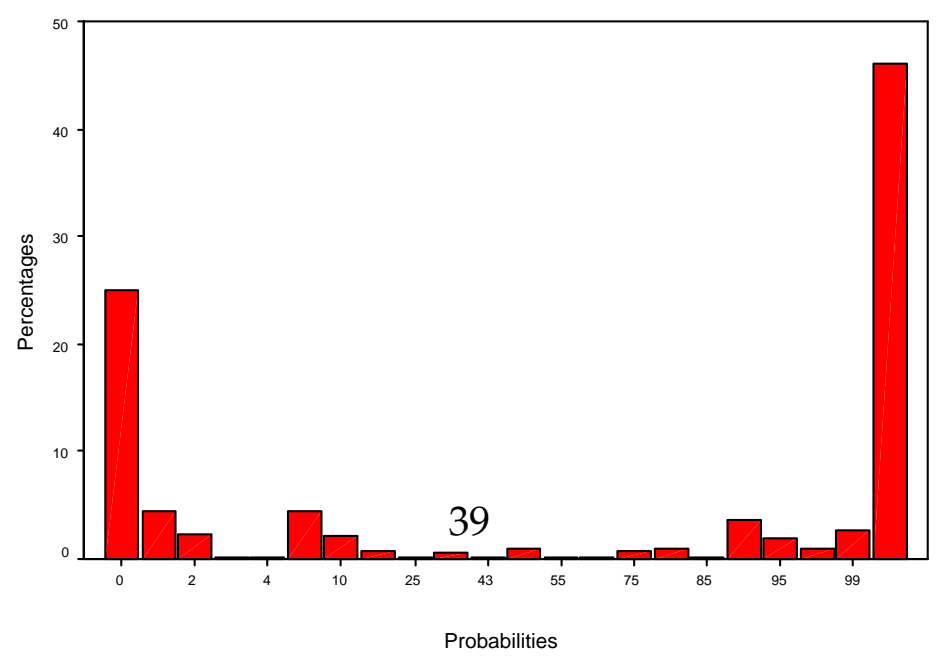

Figure 2: Distribution of proposers' subjective acceptance probabilities 
Average subjective acceptance probabilities

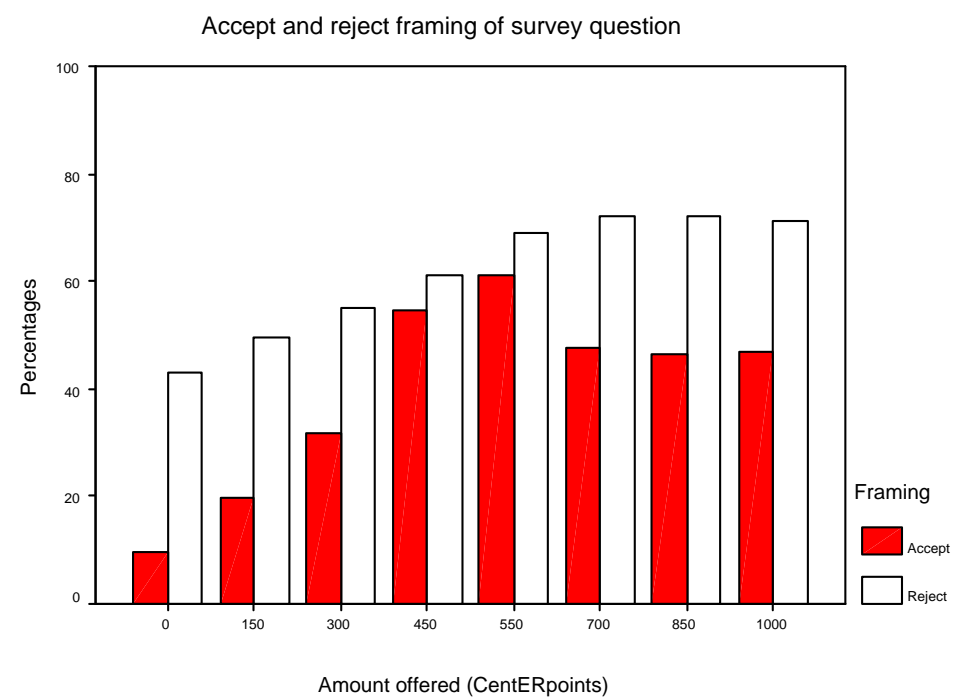

Figure 3: Beliefs of proposers in the ultimatum game for different framings of the questions 


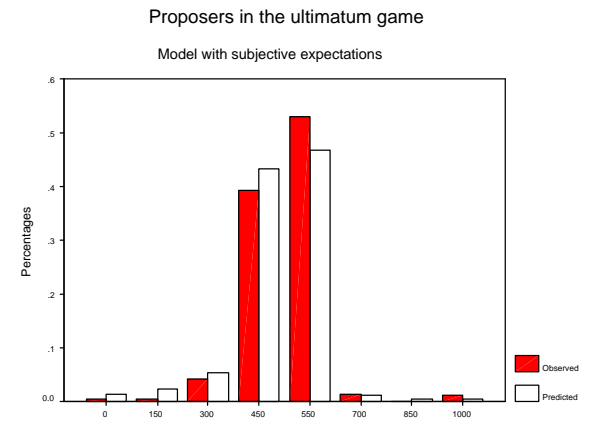

Amount offered (CenteRpoints)

Proposers in the dictator game

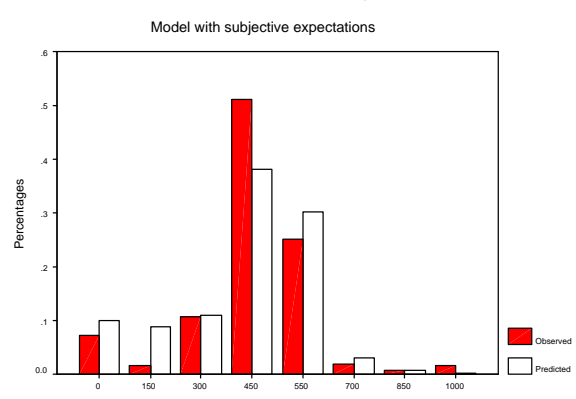

Amount offered (CentERpoints)

Responders in the ultimatum game

Model with subjective expectations

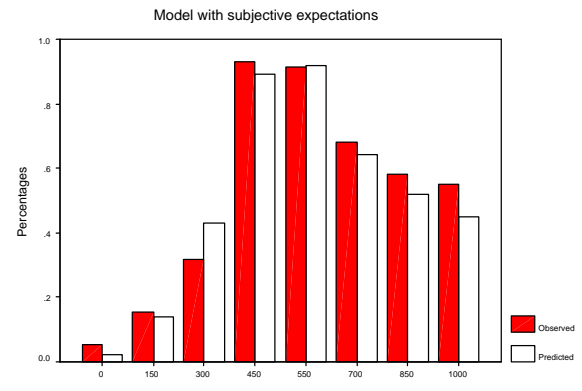

Proposers in the ultimatum game

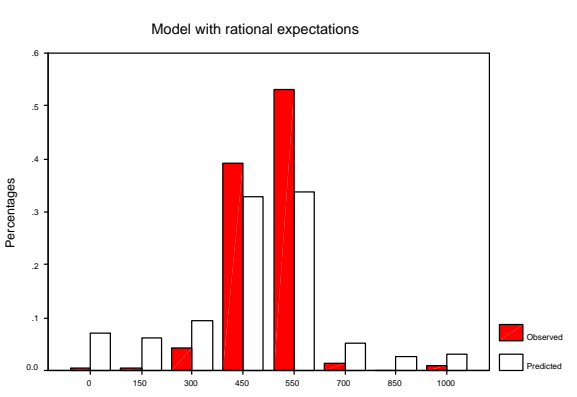

Amount offered (CentERpoints)

Proposers in the dictator game

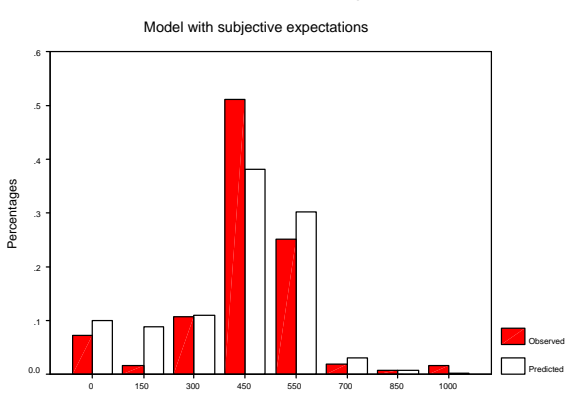

Amount offered (CentERpoints)

Responders in the ultimatum game

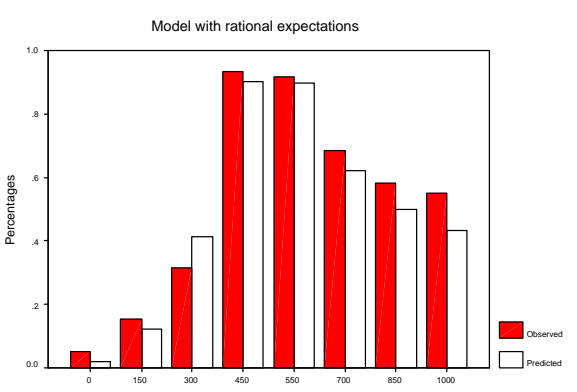

Figure 4: Left column presents observed and predicted choice distributions in the experiment using the model with subjective expectations. The right column presents observed and predicted choice distributions using the model with rational expectations. 
Predicted offers in the ultimatum game

complete model with subjective / rational expectations

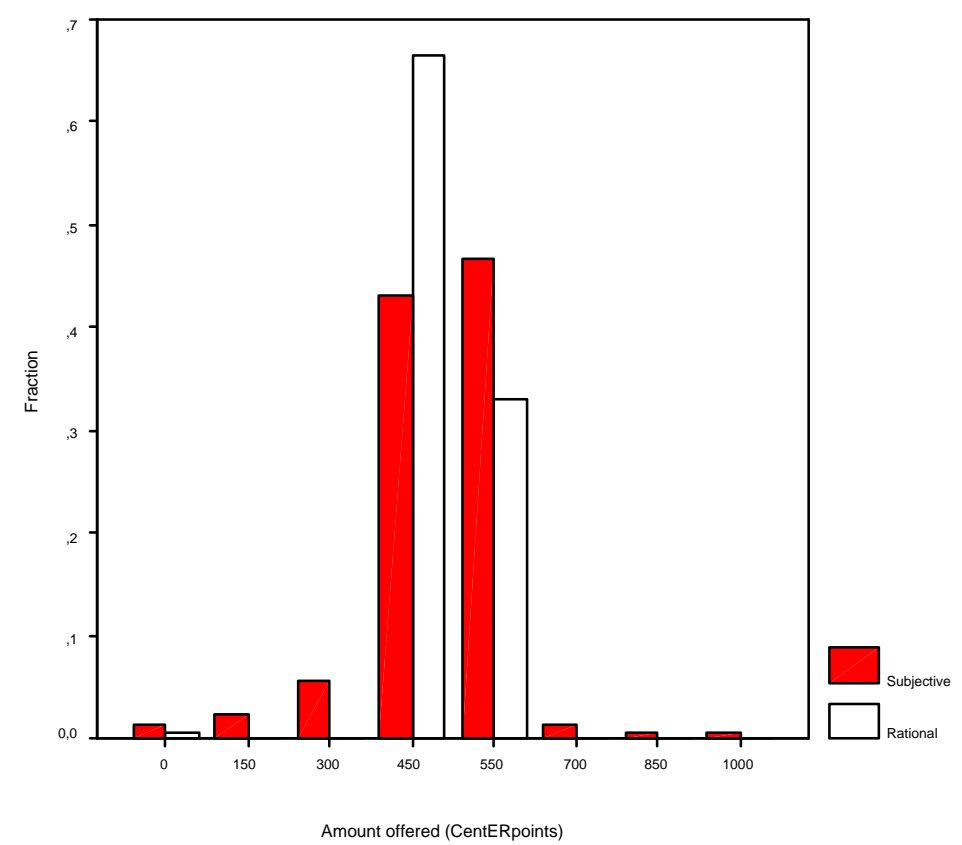

Figure 5: Predicted offer distribution in the ultimatum game using the model with subjective expectations (dark bars), predicted offer distribution setting subjective acceptance probabilities of all proposers to their sample average (white bars), and predicted offer distribution setting the subjective acceptance probabilities of all proposers to the observed acceptance rates of responders (grey bars). 


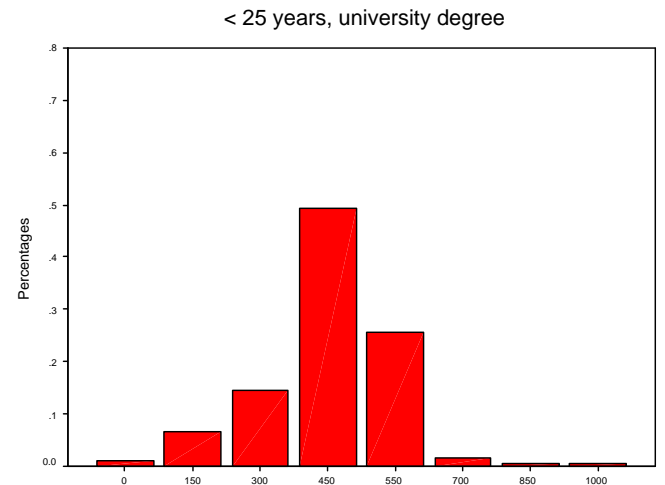

Amount offered (CentERpoints)

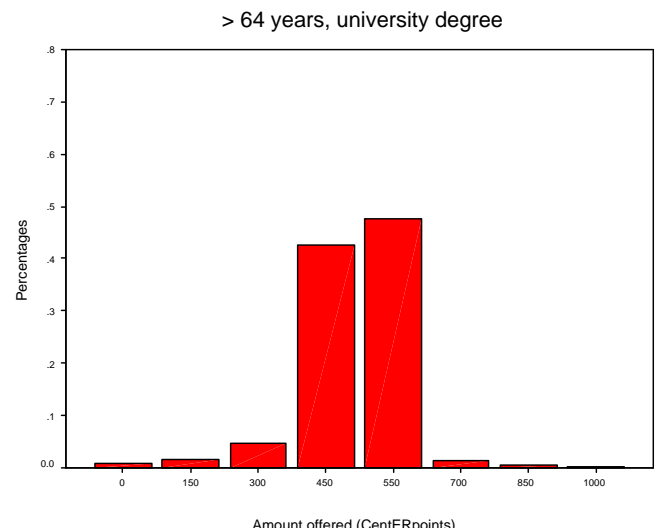

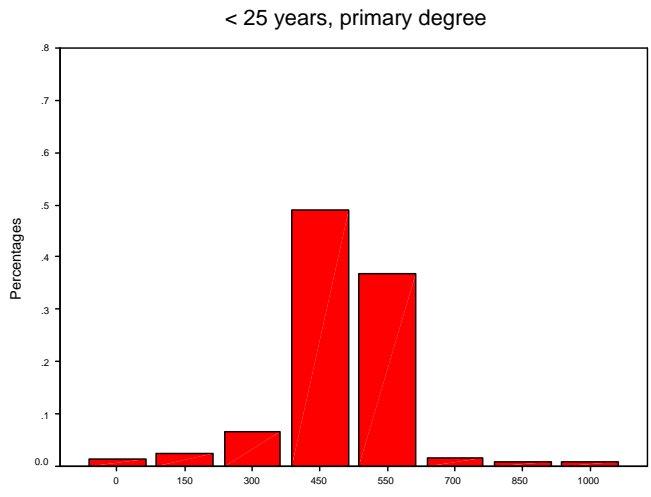

Amount offered (CentERpoints)

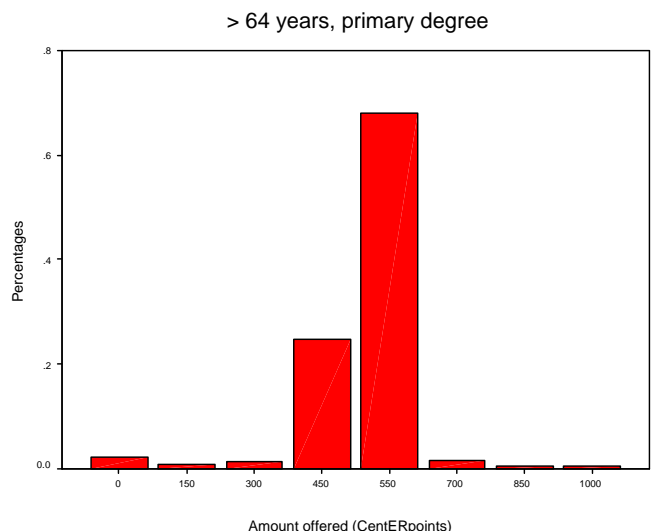

Figure 6: Predicted distributions of amounts sent by proposers in the ultimatum game for four groups: men below 25 years of age with a university degree and not working (top left), men, below 25 years of age with a primary degree and not working (top right), men above 64 years of age with a university degree and not working (bottom left), and men above 64 years of age with a primary degree and not working (bottom right). 


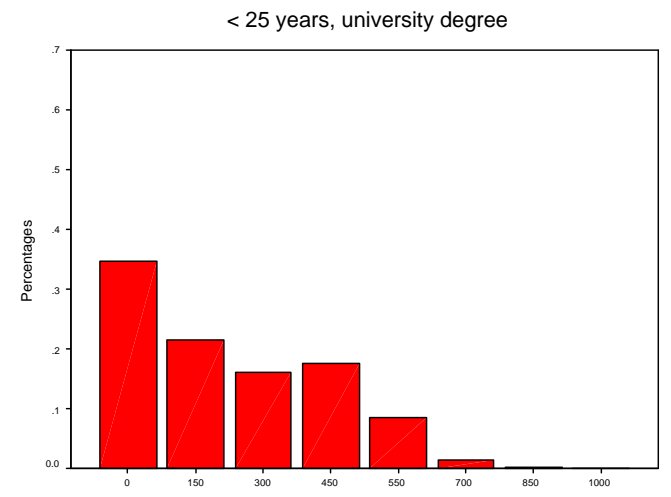

Amount offered (CentERpoints)

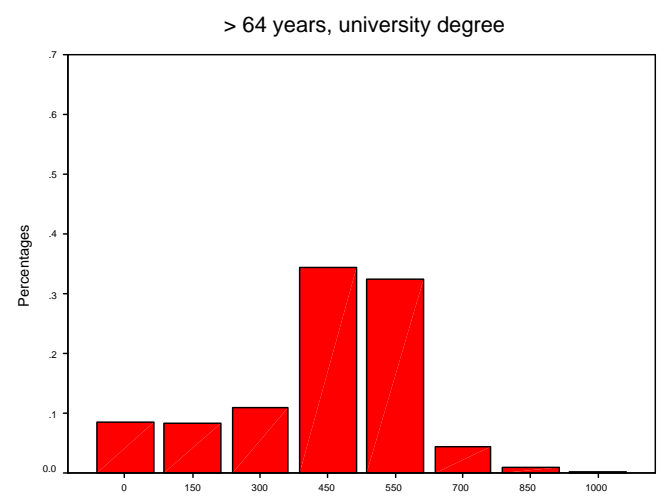

Amount offered (CentERpoints)

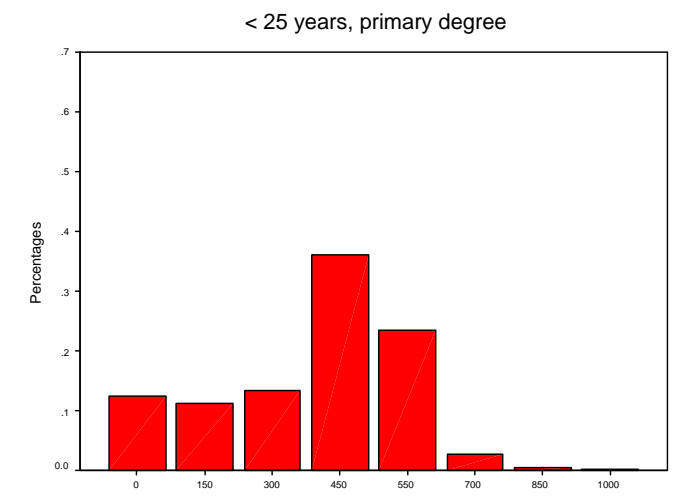

Amount offered (CentERpoints)

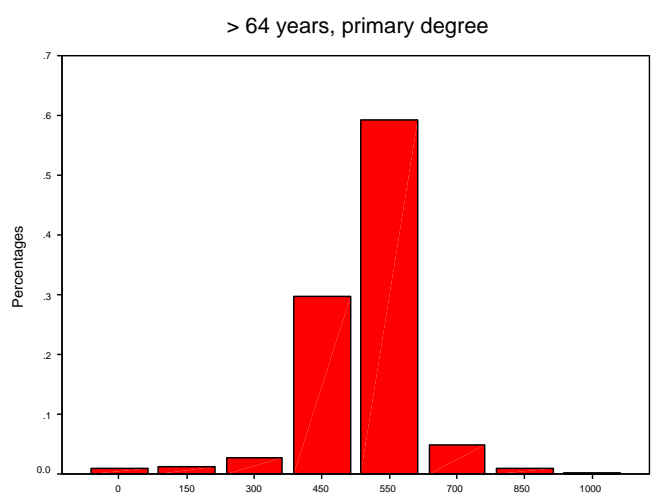

Amount offered (CentERpoints)

Figure 7: Predicted distributions of amounts sent by proposers in the dictator game for four groups: men below 25 years of age with a university degree and not working (top left), men, below 25 years of age with a primary degree and not working (top right), men above 64 years of age with a university degree and not working (bottom left), and men above 64 years of age with a primary degree and not working (bottom right). 


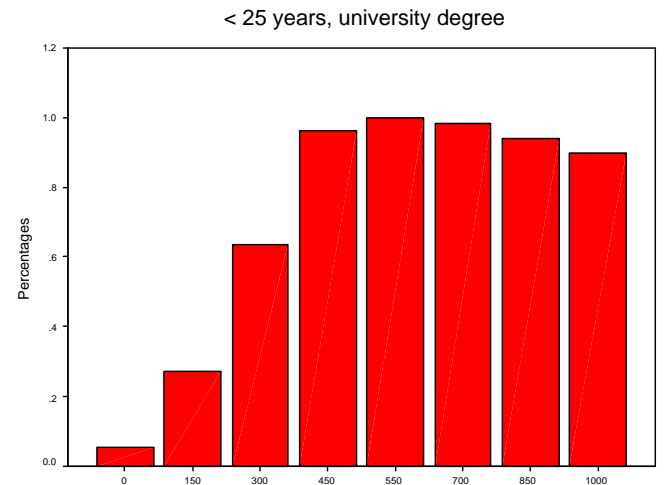

Amount received (CenteRpoints)

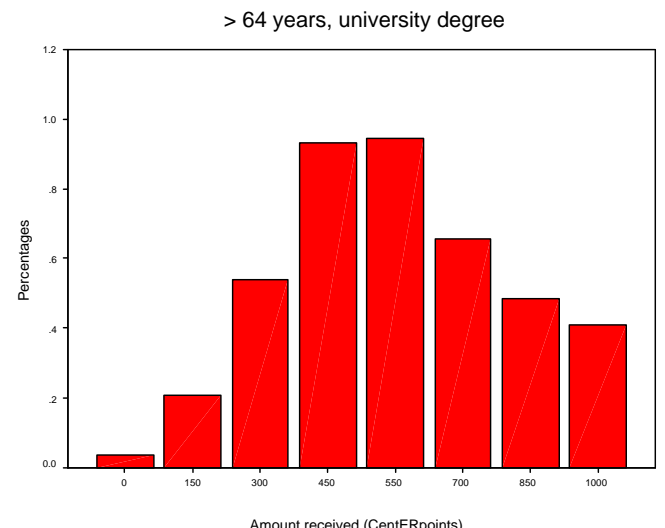

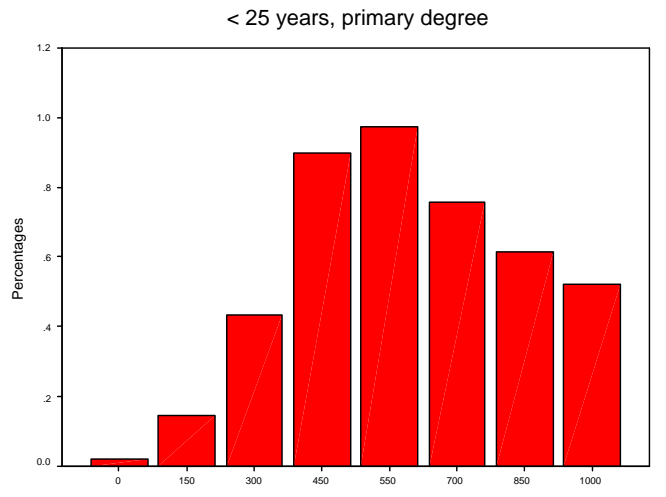

Amount received (CentERpoints)

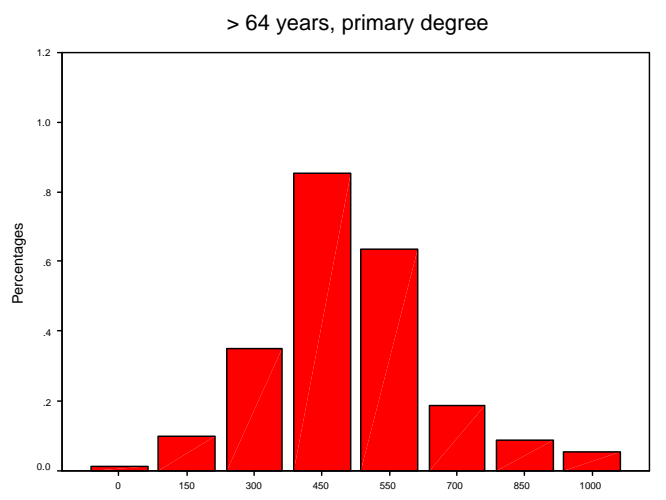

Figure 8: Predicted proportions of offers accepted by responders in the ultimatum game for four groups: men below 25 years of age with a university degree and not working (top left), men, below 25 years of age with a primary degree and not working (top right), men above 64 years of age with a university degree and not working (bottom left), and men above 64 years of age with a primary degree and not working (bottom right). 


\section{References}

Bellemare, C., And S. KRÖGER (2004): “On Representative Social Capital,” IZA Discussion Paper 1145.

Blount, S. (1995): “When Social Outcomes Aren't Fair: The Effect of Causal Attributions on Preferences," Organizational Behavior and Human Decision Process, 63, 131.

CAMERER, C. (2003): Behavioral Game Theory: Experiments on Strategic Interaction. Princeton University Press, Princeton.

CARPENTER, J., S. BurKs, AND E. VerhoOgen (2005): “Examining the Effect of Stakes in Distribution Experiments," Forthcoming, Economics Letters.

Charness, G., AND M. RABIN (2002): “Understanding Social Preferences with Simple Tests," Quarterly journal of Economics, 117, 817-869.

FeHR, E., U. Fischbacher, B. V. ROsenbladt, J. Schupp, And G. WAGNeR (2002): "A Nation-Wide Laboratory," Schmollers Jahrbuch, 122, 519-542.

FEHR, E., AND K. SCHMIDT (1999): "A Theory of Fairness, Competition and Cooperation," Quarterly journal of Economics, 114, 817-868.

FRIEDMAN, D., AND D. W. MASSARO (1998): “Understanding variability in binary and continuous choice," Psychonomic Bulletin and Review, 5, 370-389.

Goeree, J. K., And C. A. Holt (2000): "Asymmetric inequality aversion and noisy behavior in alternating-offer bargaining games," European Economic Review, 44, 10791089 .

HARrison, G. W., M. I. LAU, AND M. B. Wiliams (2002): “Estimating Individual Discount Rates in Denmark: A Field Experiment," American Economic Review, 92(5), 1606-1617.

HenNiG-SchmidT, H., Z.-Y. LI, AND C. YANG (2004): “Why People Reject Advantageous Offers: Non-monotone Strategies in Ultimatum Bargaining," Bonn Econ Discussion paper, 22.

Hoffrage, U., S. Lindsey, R. Hertwig, and G. Gigerenzer (2000): “Communicating Statistical Information," Science, 290(5500), 2261-2262.

HuCK, S., W. MÜlleR, AND H.-T. NORMANN (2001): “Stackelberg beats Cournot: On collusion and efficiency in experimental markets," Economic Journal, 111, 749-765.

Lindley, D., A. TVERSKY, And R. Brown (1979): “On the Reconciliation of Probability Assessments," Journal of the Royal Statistical Society, Series A (General), 142(2), 146-180. 
MANSKI, C. F. (2002): "Identification of Decision Rules in Experiments on Simple Games of Proposal and Response," European Economic Review, 46, 880-891. (2004): “Measuring Expectations," Econometrica, 72(5), 1329-1376.

MCLeish, K. N., AND R. OxOBY (2004): “Specific Decision and Strategy Vector Methods in Ultimatum Bargaining: Evidence on the Strength of Other-Regarding Behavior," Economics Letters, 84, 399-405.

NyARKO, Y., AND A. SchOtTer (2002): “An Experimental Study of Belief Learning Using Elicited Beliefs," Econometrica, 70(3), 971-1005.

Ortmann, A., J. FitzGerald, And C. Boeing (2000): “Trust, Reciprocity, and Social History: A Re-Examination," Experimental Economics, 3, 81-100.

Rapoport, A., And T. WAllsten (1972): “Individual Decision Behavior," Annual Review of Psychology, 23, 131-176.

SELten, R. (1967): Die Strategiemethode Zur Erforschung Des Eingeschränkt Rationalen Verhaltens im Rahmen Eines Oligopolexperimentspp. 136-168. J.C.B. Mohr (Paul Siebeck), Thübingen.

SONNEMANS, J., AND T. OfFERMAN (2001): "Is the Quadratic Scoring Rule Really Incentive Compatible?," Working paper CREED, University of Amsterdam.

Train, K. E. (2003): Discrete Choice Methods with Simulation. Cambridge University Press. 